\title{
Measurement and Modelling of the Residual Stresses in Autogenous and Narrow Gap Laser Welded AISI Grade 316L Stainless Steel Plates
}

\author{
*A. S. Elmesalamy ${ }^{1}$, H. Abdolvand ${ }^{2}$, J. N. Walsh ${ }^{2}$, J. A. Francis ${ }^{1}$, W. Suder ${ }^{3}$, S. Williams ${ }^{3}$ and L. \\ $\mathbf{L i}^{1}$ \\ ${ }^{1}$ Laser Processing Research Centre, School of Mechanical, Aerospace and Civil Engineering, \\ The University of Manchester, Manchester M13 9PL, U.K. \\ ${ }^{2}$ School of Materials, The University of Manchester, Manchester M13 9PL, U.K. \\ ${ }^{3}$ School of Aerospace, Transport and Manufacturing, Cranfield University, Cranfield MK43 0AL, U.K. \\ * Corresponding author: mesalamy76@gmail.com Cell No : 00201007999894
}

\begin{abstract}
$\underline{\text { Abstract }}$
Thick-section austenitic stainless steels have widespread industrial applications, where stresscorrosion cracking is often of major concern. Problems tend to arise in the vicinity of welds, where substantial residual stresses often reside. This paper describes an investigation into the residual stresses in autogenous high power laser welds and narrow gap laser welds (NGLW) in $10 \mathrm{~mm}$ thick AISI grade 316L steel plates, using both neutron diffraction and the contour method. The influences of laser power, welding speed and the time interval between weld passes on residual stress were analysed. For the NGLW process, finite element modelling was employed to understand the influence of thermal history on residual stress. The results for the NGLW technique show that the laser power has a significant effect on the peak value of residual stress, while the welding speed has a more significant influence on the width of the region sustaining tensile stresses.
\end{abstract}

Keywords: Computational weld mechanics, multi-pass laser welding, narrow gap welding, numerical simulation, structural integrity, weld integrity 


\section{Introduction}

The structural integrity of civil nuclear power plant components, and especially pressurised vessels and piping, will be affected by the levels of residual stress in the vicinity of welded joints [1]. Residual stresses can play a significant role in accelerating or decelerating many failure processes $[2,3]$. Residual stresses in welded joints are usually tensile in the fusion zone and heat-affected zone [4], although compressive stresses can be generated under some circumstances if solid-state phase transformations take place during the welding thermal cycles [5]. Tensile residual stresses are of particular concern because they can contribute to fatigue crack development in a structure even under compressive cyclic loading [6]. They are also considered to be the main reason for the initiation and propagation of stress corrosion cracks (SCC) in austenitic weldments [7]. In addition, the kinetics of defect growth can be affected by residual stresses. Therefore, significant research effort has been directed to understanding the development of residual stresses in power plant welds [5].

There are various techniques for measuring residual stresses. The most appropriate technique for a given application will depend on the region of interest (i.e. one might be interested in surface stresses only, or in through-thickness residual stresses). The required resolution for the residual stress measurements and the complexity of the geometry of the component are also significant factors when choosing the most appropriate measurement technique. Perhaps unsurprisingly, residual stresses in welds can be difficult to measure. Consequently, the validation of numerical methods for the prediction of residual stress distributions can be critical for improving the reliability of structural integrity assessment procedures. The ability to predict the residual stresses could also allow engineers to select welding parameters and procedures and reduce the probability of in-service failure [8].

A recent study [9] showed that the narrow gap laser welding (NGLW) technique offers potential benefits in terms of reduced levels of residual stresses for the welding of plates with thicknesses exceeding $5 \mathrm{~mm}$, when compared to other welding techniques such as gas-tungsten arc welding (GTAW) and autogenous high power laser welding. The aim of the current research is to compare the residual stresses for the NGLW technique with those for high-power autogenous laser welding, using neutron diffraction, the contour method and the finite-element modelling technique. In particular, the authors wish to establish the influence of parameters such as the laser power, the welding speed and the number of filling passes on the residual stress distributions for NGLW and autogenous laser welding. 


\section{Experimental methodology}

\subsection{NGLW preparation (Low power)}

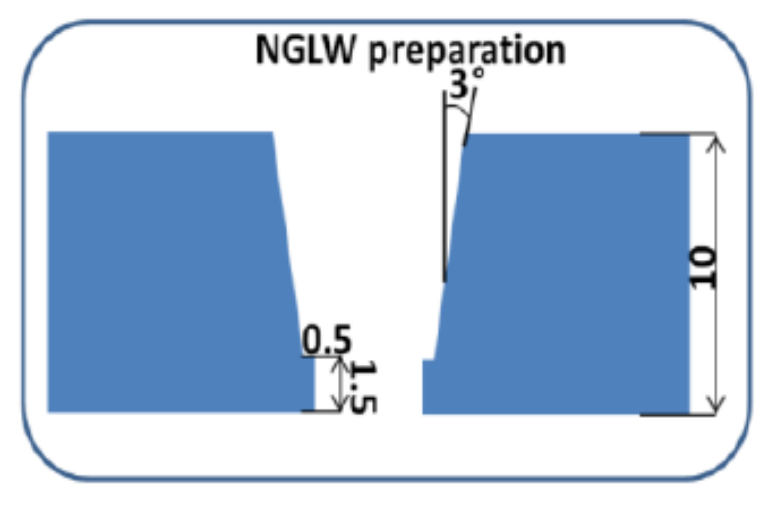

(a) Joint preparation

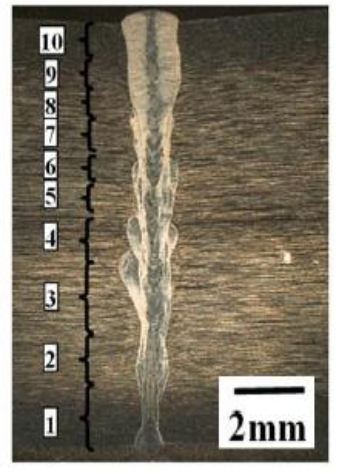

(b) Completed weld

Figure 1:. NGLW of $10 \mathrm{~mm}$ thick plates

A $1 \mathrm{~kW}$ fibre laser was used with a minimum spot diameter of $70 \mu \mathrm{m}$, and the focal point was located $2 \mathrm{~mm}$ above the top surface of the plates being joined. The spot diameter at the top surface of the sample was $\approx 220 \mu \mathrm{m}$. AISI grade 316L stainless steel filler wire with a diameter of $0.8 \mathrm{~mm}$ was used. Figure 1 shows the weld configuration and the shape of the fusion zone for a $150 \mathrm{~mm}$ (weld length) $\times 200 \mathrm{~mm}$ (width of joined plates) $\times 10 \mathrm{~mm}$ thick weld specimen. The sample was fully restrained during welding.

Pure argon was used as the shielding gas, and it was supplied co-axially through the laser nozzle, which had a diameter of $6 \mathrm{~mm}$. The welding parameters were selected based on the results of an optimization process which was reported in a previous study by the authors [10]. The purpose of this process was to optimise weld quality by eliminating weld defects and, at this stage, no account was given to the resulting levels of residual stress. A laser power of 950 $\mathrm{W}$ was used, with a welding traverse speed of $0.6 \mathrm{~m} / \mathrm{min}$, a wire feed rate of $1.1 \mathrm{~m} / \mathrm{min}$, and the distance between the tip of the gas nozzle and the surface of the welded joint (i.e. the stand-off distance) was $8 \mathrm{~mm}$. Ten passes were required in order to complete the NGLW for the $10 \mathrm{~mm}$ thick plate.

\subsection{NGLW preparation (high power)}

The joint preparation for high power NGLW of the $10 \mathrm{~mm}$ thick plates is shown in Figure 2a. The joint had a $3 \mathrm{~mm}$ root depth, a $1.5 \mathrm{~mm}$ wide root landing and a side-wall slope angle of $3^{\circ}$. The welding parameters included a laser power of $4 \mathrm{~kW}$, a welding speed of $0.7 \mathrm{~m} / \mathrm{min}$, and a nozzle stand-off distance of $108 \mathrm{~mm}$ with a spot diameter of approximately $750 \mu \mathrm{m}$. The 
diameter of the filler wire was $1.2 \mathrm{~mm}$. The specimen needed 4 filling passes as is evident from the fusion boundary profile that is shown in Figure $2 b$.

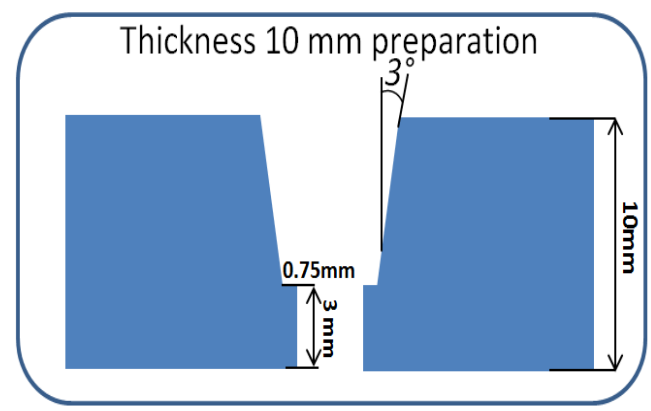

(a) Jo1nt preparation

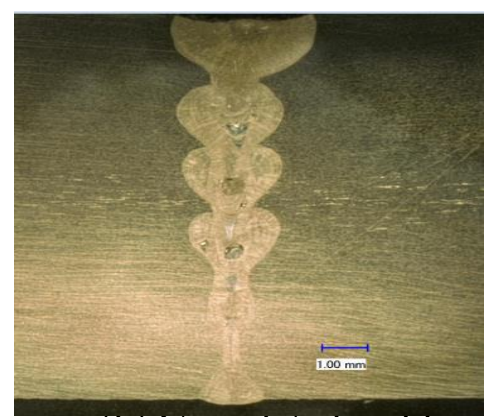

(b) completed weld

Figure 2: High power NGLW

\subsection{High power autogenous laser welding}

The autogenous laser welding parameters included a laser power of $7.5 \mathrm{~kW}$ (using an $8 \mathrm{~kW}$ IPG fibre laser), a welding speed of $0.5 \mathrm{~m} / \mathrm{min}$, a standoff distance of $145 \mathrm{~mm}$, and a spot diameter $1120 \mu \mathrm{m}$, using a square-butt weld configuration, and argon as the shielding gas. The weld cross section is shown in Figure 3.

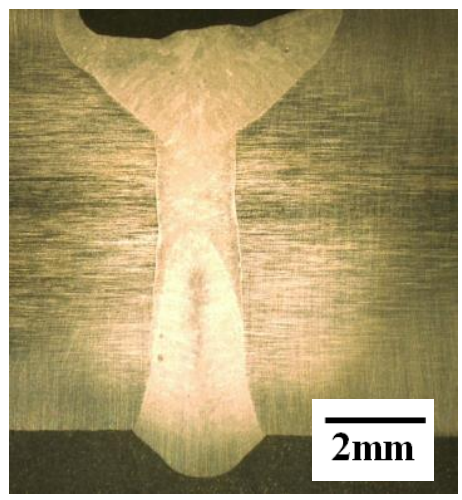

Figure 3: Weld cross section for high power autogenous laser weld

\subsection{Method and procedures for residual stress measurements}

\subsubsection{Neutron diffraction}

The neutron diffraction experiments were carried out at the Strain Analyser for Large and Small scale engineering Applications (SALSA), ILL, Grenoble, France. A monochromatic neutron beam with a wavelength of approximately $1.7 \AA$ was used to perform strain measurements. In the strain scanning setup, a position sensitive detector (PSD) was fitted, which records a single diffraction peak. 
Elastic strains in the specimen cause changes in lattice spacing, and corresponding changes in the scattering angle. By measuring these small changes in the scattering (Bragg) angle, it is possible to obtain the elastic strain in the lattice by using Bragg's law, and hence to obtain the bulk strain in three orthogonal directions [11]. In polycrystalline austenitic stainless steels the $\{311\}$ crystal plane is considered to be suitable for residual stress measurements [12], because the reflections exhibit an approximately linear response to lattice strain as plasticity starts to occur. This means that they give a good representation of the macroscopic elastic strain, with minimal sensitivity to inter-granular and inter-phase stresses.

The incident and diffracted neutron beams are defined by slits or collimators. The gauge volume is defined by the intersection of the incident and diffracted beams, which defines the region used to calculate the average stress. In this work a gauge volume of $1 \mathrm{~mm} \times 1 \mathrm{~mm} \times 1 \mathrm{~mm}$ was used owing to the very narrow fusion zone and the expectation that the residual stress distribution would exhibit steep gradients. In order to obtain a stress value, it is usually necessary to measure strains in three orthogonal sample orientations (e.g. longitudinal-transverse-normal).

Elastic strains and stresses were determined at the mid-length position of the weld. The locations of the measurements for each sample are shown in Figure 4. The distances between measurement points were very small near the fusion zone, such that $X_{1}=1 \mathrm{~mm}$ for the NGLW sample, over a width of $20 \mathrm{~mm}$ (i.e. 20 measurements for each depth within the plate).
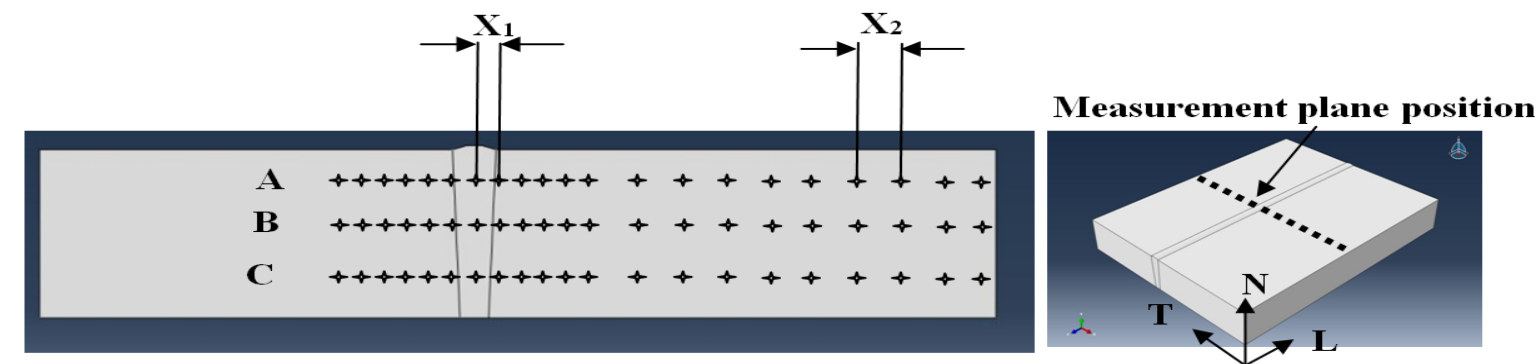

Figure 4. Locations for neutron diffraction measurements

These measurements were repeated at three different levels, A, B and C; levels A and C were 2 $\mathrm{mm}$ away from the upper and lower surface of the plate, respectively, and level B was at the mid-depth position. The horizontal distance between measurements at a given depth increased toward the edges of the plates, due to an expected decrease in the stress gradients. The distance $\mathrm{X}_{2}$ was $5 \mathrm{~mm}$ for the rest of the workpiece.

Once the lattice spacing of the welded samples was determined at each measurement location, the strain in the same direction was calculated using the following equation. 


$$
\varepsilon_{L(x, y)}=\frac{d_{L(x, y)}-d_{r e f(x, y)}}{d_{r e f(x, y)}}
$$

where $\varepsilon_{\mathrm{L}(\mathrm{x}, \mathrm{y})}$ is the calculated longitudinal strain at point $(\mathrm{x}, \mathrm{y}), d_{L(x, y)}$ is the lattice spacing measured in longitudinal orientation at point $(\mathrm{x}, \mathrm{y})$, and $d_{r e f(x, y)}$ is the stress-free lattice spacing at point $(\mathrm{x}, \mathrm{y})$. Figure 4 shows the longitudinal $(\mathrm{L})$, transverse $(\mathrm{T})$ and normal $(\mathrm{N})$ directions with respect to the welded joint.

In order to obtain the stress-free lattice spacing, $d_{r e f(x, y)}$, comb-shaped strain-free reference $\left(d_{r e f}\right)$ specimens were prepared. These specimens were required so that position-dependent values for the stress-free lattice parameter could be determined across the weld. The samples were prepared by electric discharge machining (EDM), using skim cutting conditions to minimize the probability of introducing any additional stresses due to the cutting operation. The configuration of the comb-shaped specimens is shown in Figure 5. The slice thickness was $3.6 \mathrm{~mm}$. It was extracted from the welded joint, and then the comb teeth were created with further EDM cuts, so that each comb tooth had a cross-section measuring $3.6 \mathrm{~mm} \times 3.6 \mathrm{~mm}$. Each comb tooth provides a (nominally) stress-free region that can be used to measure $d_{\text {ref }}(x, y)$ [13], where $Y_{i}$ is the depth of each tooth, which was $8 \mathrm{~mm}$ in the $10 \mathrm{~mm}$-thick samples. The dimensions of each comb tooth had been calculated and cut precisely to ensure that the gauge volume was completely immersed within an individual comb tooth [14].

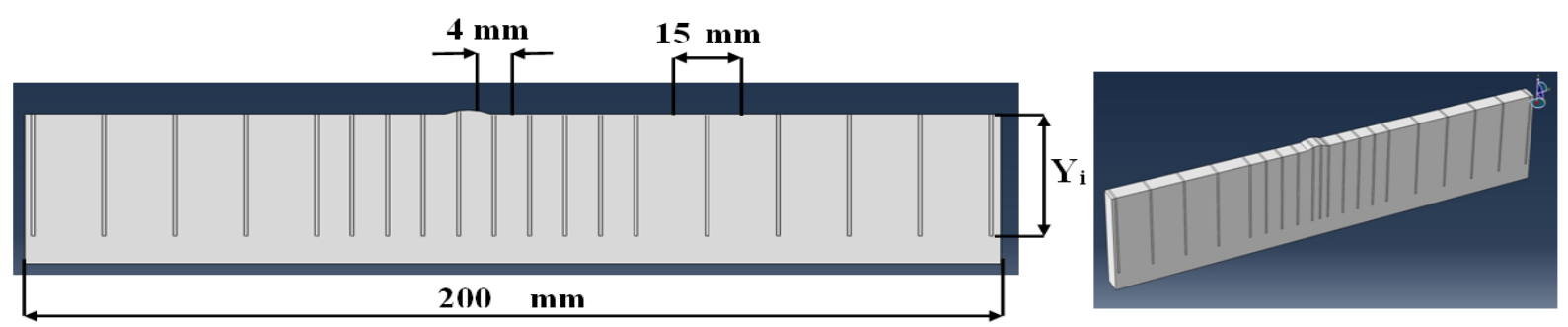

a - Details of distances between comb teeth b - Overview of the comb specimen Figure 5: Schematic representation of the strain-free comb $\left(\mathrm{d}_{\mathrm{ref}}\right)$ specimens

The strains in the normal $\varepsilon_{N}$ and transverse $\varepsilon_{T}$ directions were calculated in a similar manner. The stress acting in the longitudinal orientation, at point $(\mathrm{x}, \mathrm{y})$ in the measurement plane, can then be calculated using a generalised version of Hooke's law, according to the following equation:

$$
\sigma_{L(x, y)}=\frac{E_{\{311\}}}{1+v_{\{311\}}}\left[\varepsilon_{L(x, y)}+\frac{v_{\{311\}}}{1-2 v_{\{311\}}}\left(\varepsilon_{L(x, y)}+\varepsilon_{T(x, y)}+\varepsilon_{N(x, y)}\right)\right]
$$


where $\mathrm{E}_{\{311\}}$ and $v_{\{311\}}$ are the plane specific values of the elastic modulus and Poisson's ratio respectively, determined from in-situ tensile diffraction data. The values of $\mathrm{E}_{\{311\}}$ and $v_{\{311\}}$ were taken to be $193 \mathrm{GPa}$ and 0.28 respectively, and these steps were repeated to calculate the normal and transverse components of stress.

\subsubsection{Contour method}

The contour method was developed by Prime [18] and it is based on a variant of Bueckner's superposition principles [15,16]. Many researchers, e.g. Kartal et al. [17], Withers et al. [18] and Edwards et al. [8] have used this technique successfully for the evaluation of the residual stresses in various welded joints. A detailed description of the technique is given elsewhere [14].

\section{Finite element modelling of NGLW process}

Residual stress in welds has a complex dependence on many interacting variables, including geometry, welding parameters, process constraints (boundary conditions), and material properties. Many assumptions have to be made in the analysis, particularly in cases where both the thermal and mechanical responses have to be simulated [19]. Many FE models have been developed previously to understand and simulate the conventional GTA welding process $[20,21]$ and autogenous laser welding process [22]; however, there is little knowledge relating to the evolution of residual stress in NGLW and also little understanding of the effects of welding parameters on the final stress distribution.

This study uses the finite element (FE) modelling technique to study residual stress development in narrow gap laser welding using the ABAQUS Welding Interface (AWI).

\subsection{Finite element modelling of laser heat source}

The ABAQUS Welding Interface (AWI) module is a newly developed module for modelling multi-pass welding processes, based on an element birth and death technique, to simulate a moving heat source and weld filler deposition as a function of time in each single pass. This welding module provides the capability to improve two- and three-dimensional numerical welding simulations by automating most of the tasks associated with building a welding finite element model.

In the present investigation, the AWI module was used to simulate the development of the residual stress distribution in NGLW joints. The influence of inter-pass time on the residual 
stresses was investigated. The influence of welding parameters (speed, power) on the development of stress was also investigated in order to optimise the welding procedures. The heat source that was applied in the AWI was modified to simulate the actual thermal profile across the weld bead for the laser welding techniques, as will be discussed in detail in next sections. Modelling of the welded samples was based on the sample dimensions used in the experiments, which included a weld length of $150 \mathrm{~mm}$ and a plate width of $200 \mathrm{~mm}$, as is shown in

Figure 6.

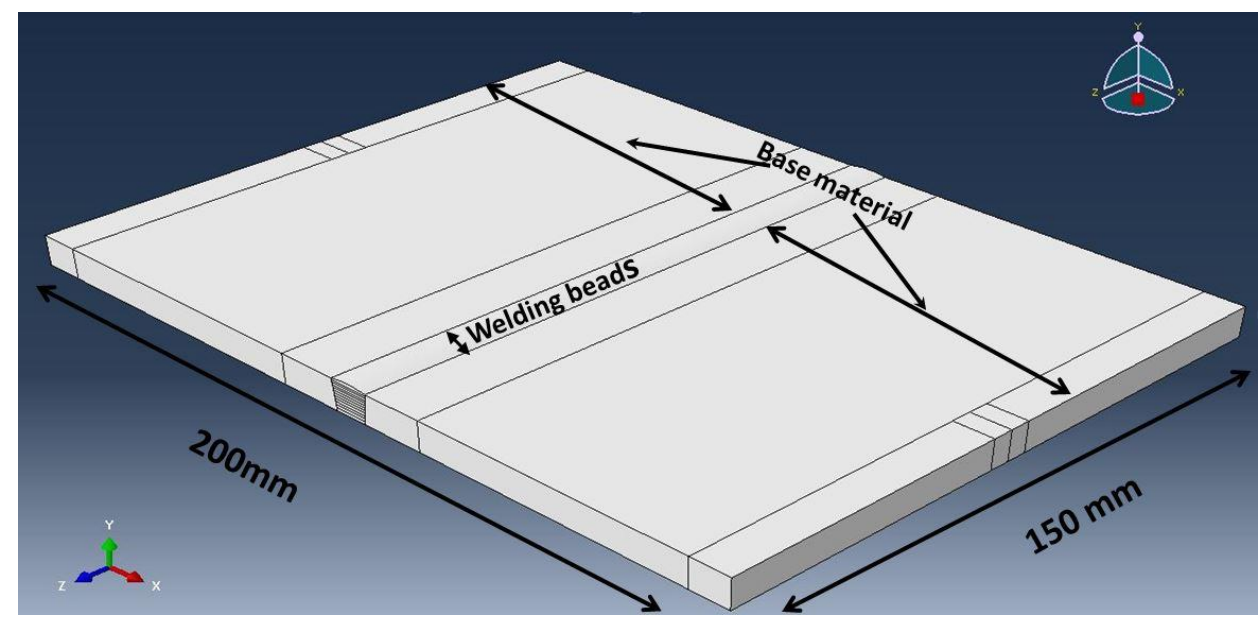

Figure 6. Model dimensions and definition according to the geometry used in experiments.

The material properties given in Table 1 were used for the FE simulation. External surfaces for the welded joint (i.e. those surfaces in contact with the surrounding environment), and the interfaces (i.e. the boundaries between individual weld beads and between the fusion zone and the adjacent parent material) had to be defined, as is shown in Figure 7. The convective and radiation boundary conditions (BCs) also needed to be defined for the top surface of the weld beads, as well as for the surfaces exposed at each end of the beads, and at the sides, as well as for the interfaces between the weld beads, and for the base material.

Meshing of the model was performed using different densities according to temperature gradients and stress variation across the welded joint. A high-density mesh was used near to the fusion zone. Figure 7 shows modelled and real weld bead cross sections for NGLW of $10 \mathrm{~mm}$ thick plates. 
Table 1 Material properties for 316L stainless steel at different temperatures [22]

\begin{tabular}{|c|c|c|c|c|c|c|c|c|}
\hline Temperature & $\begin{array}{c}\text { Density } \\
{\left[\mathrm{Kg} / \mathrm{m}^{3}\right]}\end{array}$ & \begin{tabular}{rl|c|c|c|} 
Conductivity \\
{$\left[\mathrm{Wm} /{ }^{\circ} \mathrm{C}\right]$}
\end{tabular} & $\begin{array}{c}\text { Specific } \\
\text { heat } \\
{[\mathrm{KJ} / \mathrm{Kg}} \\
\left.{ }^{\circ} \mathrm{C}\right]\end{array}$ & $\begin{array}{c}\text { Thermal } \\
\text { expansion } \\
\text { coeff. } \\
{\left[\mathrm{mm} / \mathrm{mm}^{\circ}{ }^{\circ} \mathrm{C}\right]}\end{array}$ & $\begin{array}{c}\text { Young } \\
\text { Modulus } \\
{[\mathrm{GPa}]}\end{array}$ & $\begin{array}{c}\text { Poisson's } \\
\text { Ratio }\end{array}$ & $\begin{array}{c}\text { Yield strength } \\
(0.2 \% \text { proof }) \\
{[\mathrm{MPa}]}\end{array}$ & $\begin{array}{c}\text { Yield(1\% plastic } \\
\text { strain }) \\
{[\mathrm{MPa}]}\end{array}$ \\
\hline 20 & 7979 & 13.31 & 0.47 & 15.24 & 195 & 0.267 & 278 & 325 \\
\hline 100 & 7937 & 14.68 & 0.487 & 15.8 & 191 & 0.273 & 233 & 272 \\
\hline 500 & 7760 & 20.96 & 0.571 & 17.85 & 164 & 0.313 & 146 & 171 \\
\hline 1000 & 7535 & 27.53 & 0.676 & 19.38 & 100 & 0.229 & 35 & 40 \\
\hline 1200 & 7430 & 29.76 & 0.719 & 19.95 & 59.5 & 0.223 & 12 & 15 \\
\hline 1400 & 7320 & 31.95 & 0.765 & 20.6 & $2^{*}$ & 0.223 & 3 & 3.3 \\
\hline 1500 & 7320 & $320^{*}$ & 0.765 & 20.7 & $2^{*}$ & 0.223 & 3 & 3.3 \\
\hline
\end{tabular}

The generalised differential equation, which represents heat conduction in a solid body in the AWI is:

$$
\frac{\square}{\square x}\left(k_{x} \frac{\square T}{\square x}\right)+\frac{\square}{\square y}\left(k_{y} \frac{\square T}{\square x}\right)+\frac{\square}{\square z}\left(k_{z} \frac{\square T}{\square x}\right)+Q=\rho C \frac{\square T}{\square t}
$$

Where $k_{x}, k_{y}, k_{z}$ are the thermal conductivity coefficients in the $\mathrm{x}, \mathrm{y}$ and $\mathrm{z}$ directions respectively. $\mathrm{T}$ is the current temperature, $\mathrm{Q}$ is the rate of internal heat generation, $\rho$ is the density, $C$ is the specific heat and $\mathrm{t}$ is the time. The general solution is obtained by applying initial and boundary conditions as follows:

\section{Boundary conditions are:}

Initial condition

Convection

Radiation

$$
\begin{gathered}
T(x, y, z, 0)=T_{0}(x, y, z) \\
Q_{c}=h_{c} A\left(T-T_{\infty}\right) \\
Q_{r}=\sigma \varepsilon A\left(T^{4}-T_{\infty}{ }^{4}\right)
\end{gathered}
$$

Where $h_{c}$ is the convective heat-transfer coefficient, $A$ is the surface area subjected to convection, radiation, and $\varepsilon$ is the body emissivity. $\mathrm{T}_{\infty}$ is the ambient temperature.

$$
\begin{aligned}
& Q_{t}=Q_{c}+Q_{r}=\sigma \varepsilon A\left(T^{4}-T_{\infty}{ }^{4}\right)+h_{c} A\left(T-T_{\infty}\right) \\
= & \sigma \varepsilon A\left(T^{2}+T_{\infty}{ }^{2}\right)\left(T-T_{\infty}\right)\left(T+T_{\infty}\right)+h_{c} A\left(T-T_{\infty}\right) \\
= & A\left(T-T_{\infty}\right)\left[\sigma \varepsilon\left(T^{2}+T_{\infty}{ }^{2}\right)\left(T+T_{\infty}\right)+h_{c}\right]
\end{aligned}
$$

The equation could be written in the following form:

$$
Q_{t}=h_{t} A\left(T-T_{\infty}\right)
$$

where $Q_{t}$ is the total heat transfer due to convection and radiation, $\mathrm{h}_{\mathrm{t}}$ is the total heat transfer coefficient or film coefficient, such that

$$
h_{t}=\sigma \varepsilon\left(T^{2}+T_{\infty}^{2}\right)\left(T+T_{\infty}\right)+h_{c} .
$$


For the ten pass NGLW model of the weld in a $10 \mathrm{~mm}$ thick plate, the number of elements in the $\mathrm{x}$ direction $n_{x}$ was 60 , the number of elements in the $\mathrm{y}$ direction $\mathrm{n}_{\mathrm{y}}$ was 100 , and the number of elements in the $\mathrm{z}$ direction $n_{z}$ was 10 . In the heat transfer analysis linear DC3D8 elements were used, and for the stress analysis C3D8 elements were used. Both types of element are 8 node linear brick elements, as shown in Figure 7. The order of passes (real and modelled) for the $10 \mathrm{~mm}$ thick sample was based on the sequence shown in Figure 7.

A weld pass is divided into basic units called chunks, which define the birth units. Then the number of elements per chunk has to be defined. If the number is 1 that means the birth unit (chunk) will consist of one element. One element will be deposited on the plate once the heat source approaches.
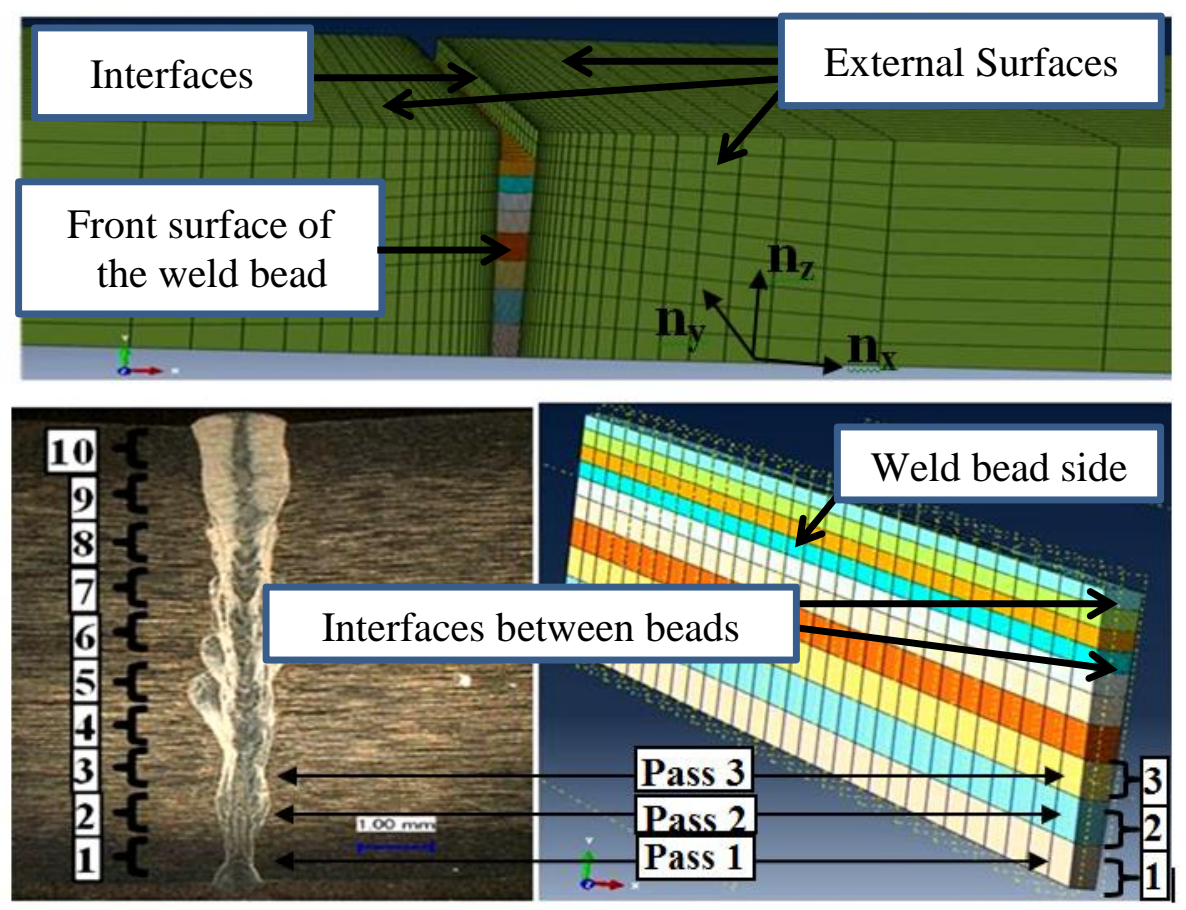

Figure 7. Modelled and real weld bead cross sections for NGLW of $10 \mathrm{~mm}$ thick plates

The traverse speed for the heat source can be controlled through specifying the time period (the time required to apply the heat source to one element). The time for a step is specified by the user according to real welding parameters. In this study, for the NGLW technique, the real weld pass length was $150 \mathrm{~mm}$, and the number of elements in the direction of welding was 100 . The element length was $1.5 \mathrm{~mm}$, and the time period was $0.15 \mathrm{~s}$ per element. This corresponds to a welding speed of $600 \mathrm{~mm} / \mathrm{min}$. The cool down time between successive passes was 30 min. The heat associated with welding was applied as a temperature profile in the AWI model. The AWI assumes a prescribed temperature during weld bead generation in order to represent 
the heat source. One of the limitations of the AWI is that the temperature is assumed to be uniform across the weld bead. Figure 8 shows the thermal profiles for a laser heat source at different welding speeds, for a peak temperature of $2500{ }^{\circ} \mathrm{C}$.

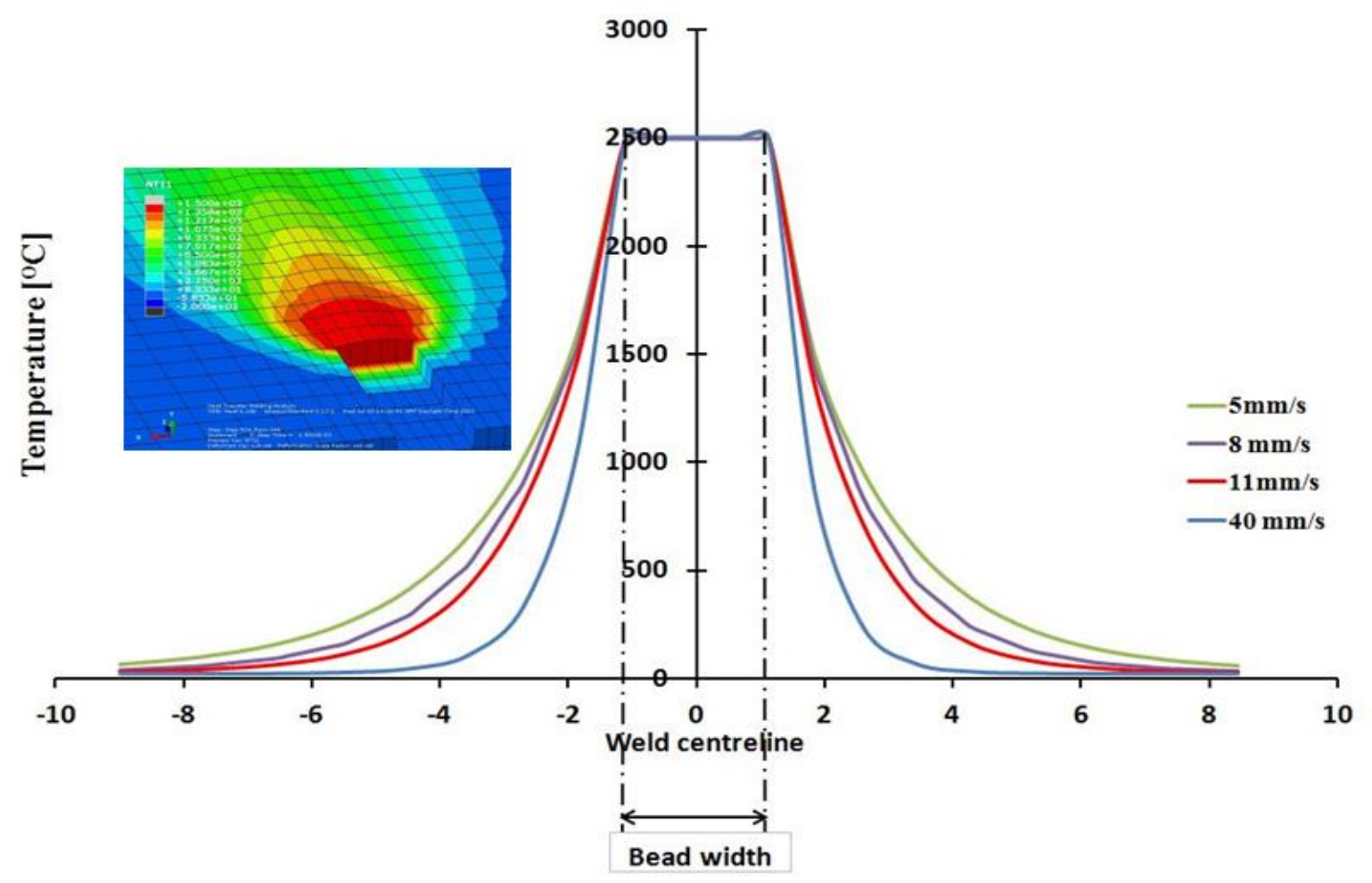

Figure 8. Thermal profiles for the heat source in NGLW at different welding speeds

Gaussian heat source profiles have been used for numerical simulation of autogenous laser welding [23,24]. However, a parabolic profile is considered to offer the best fit for the temperature distributions in laser welding [23]. In the present work, a parabolic function was employed for the temperature profile across the laser weld bead, as the experimental work was based on a single mode $1 \mathrm{~kW}$ fibre laser. A peak temperature of $3000^{\circ} \mathrm{C}$ was used to generate the weld bead for a $1 \mathrm{~kW}$ fibre laser, and the temperature at the edge of the weld bead, which was on average $0.5 \mathrm{~mm}$ from the weld centreline, was $1500^{\circ} \mathrm{C}$ [24].

\subsection{Experimental validation}

Four K-type thermocouples were attached to the upper surface of the $10 \mathrm{~mm}$ thick welded joint for the NGLW process. Thermocouples were located on the top surface of the sample at distances of $0.5,1,1.5$, and $2 \mathrm{~mm}$ from the edge of the groove at the mid-length position of the weld. The measurements were carried out for the last pass, which was the nearest to the 
thermocouples. A laser power of $950 \mathrm{~W}$ was used, with a welding traverse speed of $0.6 \mathrm{~m} / \mathrm{min}$, a wire feed rate of $1.1 \mathrm{~m} / \mathrm{min}$, and a stand-off distance of $8 \mathrm{~mm}$.

\section{Results and discussion}

\subsection{Experimental validation}

Figure 9 shows the measured thermal cycles for the NGLW process at different locations. The results show that the measured peak temperature was $1450^{\circ} \mathrm{C}$ at a distance of $0.5 \mathrm{~mm}$ from the edge of the weld groove. The measured peak temperature decreases to $1150^{\circ} \mathrm{C}$ at a distance of $1 \mathrm{~mm}$, and to $800{ }^{\circ} \mathrm{C}$ at $1.55 \mathrm{~mm}$, and finally to $250{ }^{\circ} \mathrm{C}$ at $2 \mathrm{~mm}$. These values will be used for validation of the thermal analysis.

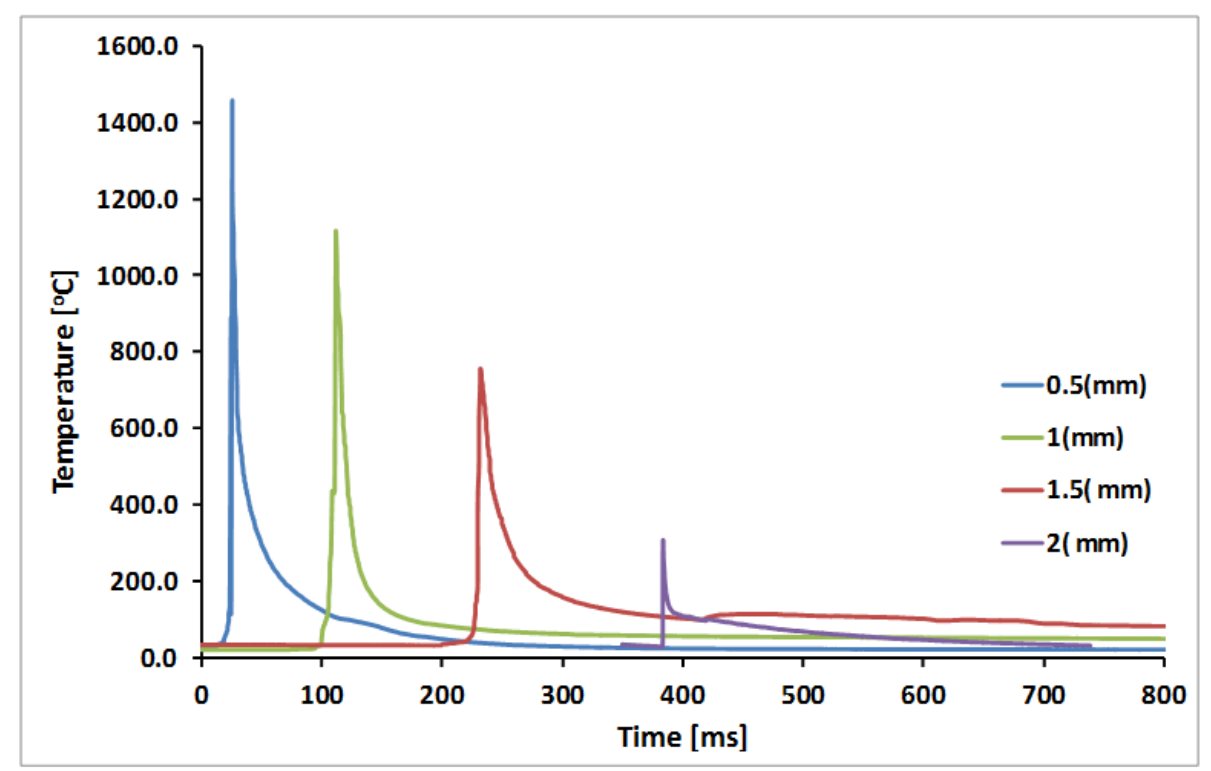

Figure 9. Measured temperature transients for the last pass in a NGLW specimen as a function of distance from the edge of the weld groove.

The 2D parabolic temperature distribution for the deposition of the weld bead can be described as follows;

$$
T(x, y)=\left[T_{\text {peak }}-T_{\text {interface }}\right]\left[1-\frac{x^{2}+y^{2}}{R^{2}}\right]+T_{\text {interface }}
$$

where $T_{\text {peak }}$ is the peak temperature at the centre of the weld bead; $T_{\text {interface }}$ is the temperature at the interface between the fusion zone and the base material; $x$ and $y$ are the Cartesian coordinates of the measured point with respect to the centre of the weld bead and $R$ is the radius of the weld bead. 
Figure 10 shows the results of FE simulations for two modified heat source (parabolic) representations and compares them with values measured in experiments.

The results show there is close agreement between measured temperatures and those predicted by the numerical models. The weld temperature profile is shown in Figure 10 as a sample output from the thermal analysis. The influence of the interface temperature was also investigated. The modelling was repeated with a different interface temperature $\left(1700^{\circ} \mathrm{C}\right)$. The results showed that the interface temperature has a more significant influence on the accuracy of predicted temperature fields. Consequently a parabolic profile was used for the temperature distribution in this work together with an assumed interface temperature of $1500{ }^{\circ} \mathrm{C}$.

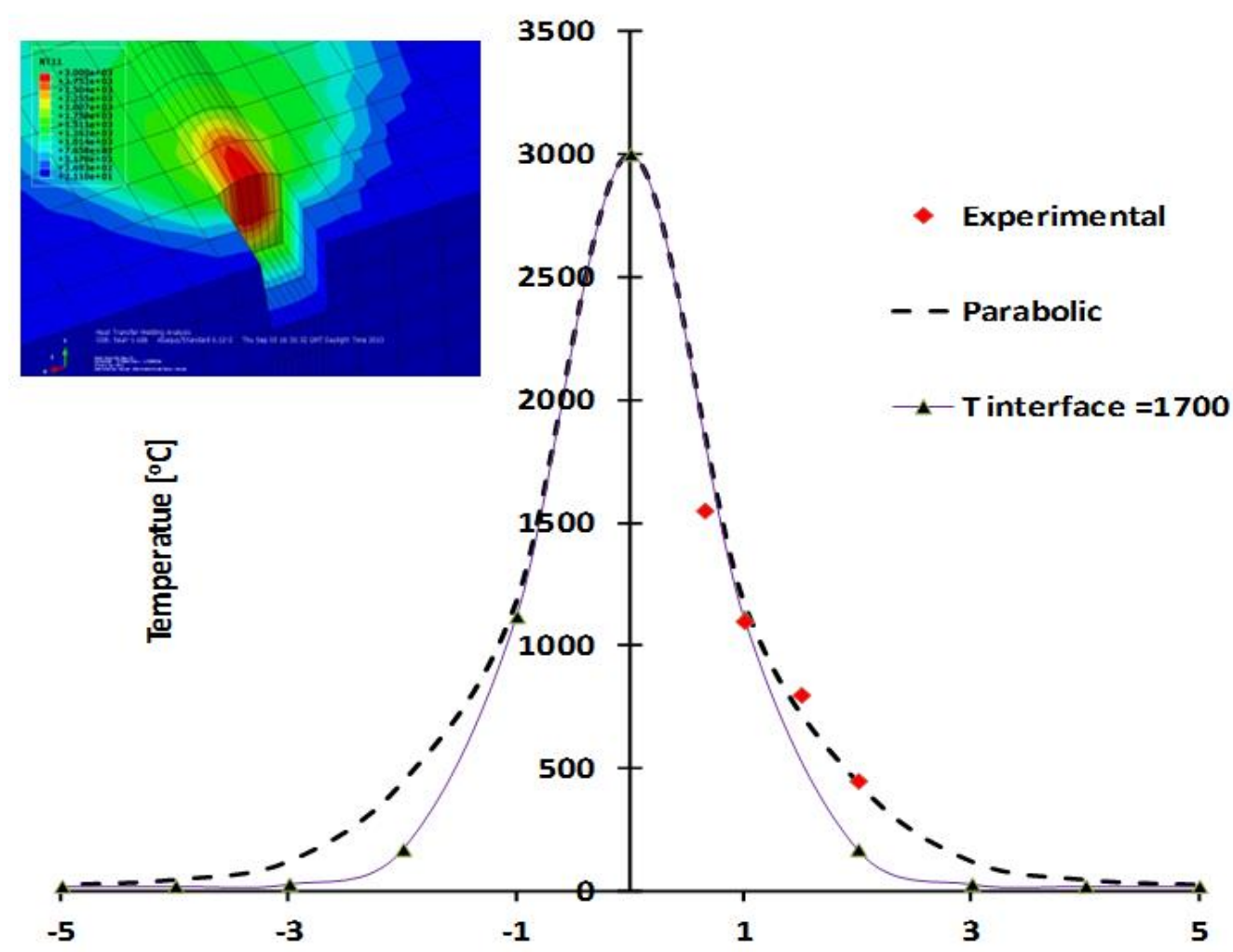

Figure 10. NGLW thermal analysis validation of NGLW

\subsection{Residual stress distributions for low power NGLW}

Figure 11 shows the distribution of longitudinal residual stresses for the single-sided NGLW sample, as measured by the contour method. It can be seen that the residual stresses for the NGLW are approximately symmetrical about the weld centreline.

The stresses in the vicinity of the weld centreline are tensile, with the peak tensile stresses being close to $350 \mathrm{MPa}$ in magnitude, and they occur approximately $3 \mathrm{~mm}$ below the upper surface of the specimen on the weld centreline. The tensile stresses decreased rapidly with 
distance from the weld centreline, and compressive stresses were measured over significant areas of the measurement plane. The width of the region sustaining tensile residual stresses was approximately $15 \mathrm{~mm}$.
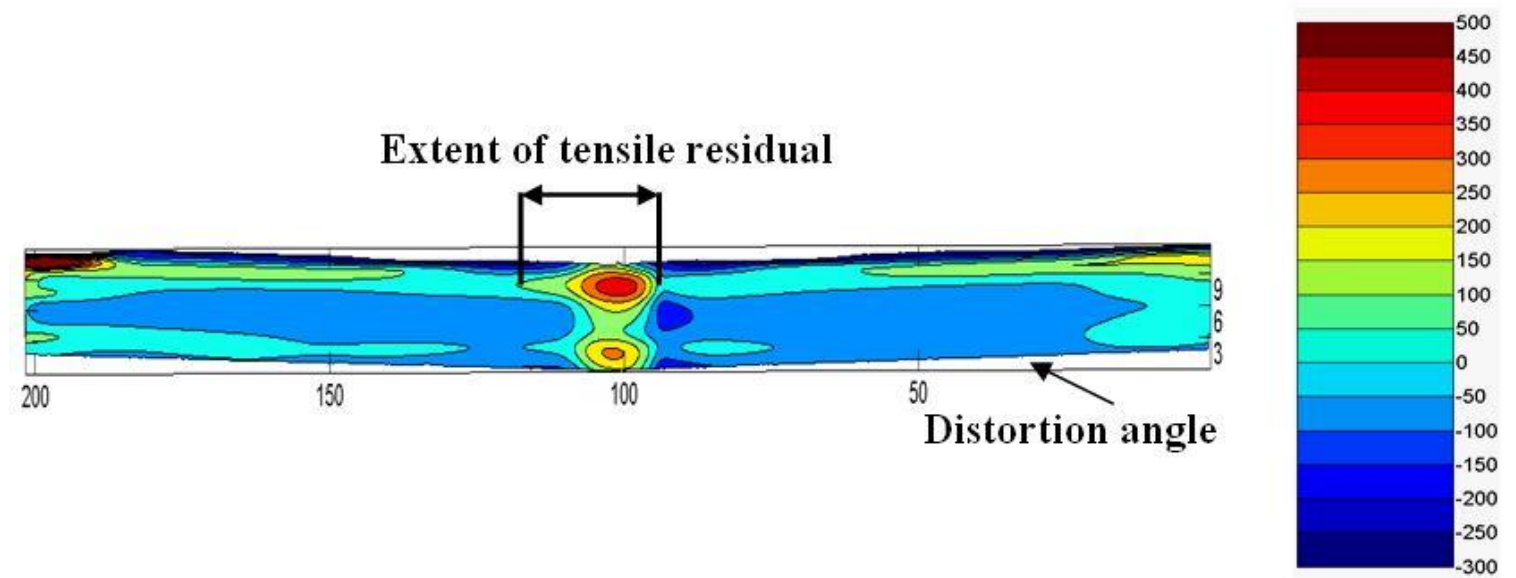

Figure 11: Longitudinal residual stresses in low power NGLW in $10 \mathrm{~mm}$ thick plate, as measured by the contour method [MPa]

\subsection{Residual stress distributions for high power NGLW}

The residual stress distribution for the high power NGLW experiment is shown in Figure 12. The plot shows that the distribution is approximately symmetric. The peak stress is close to 600 $\mathrm{MPa}$ in tension. With the higher power, a lower number of passes was required to fill the joint. However, the value of the peak stress and the extent of the tensile region both appear to be larger than for the low power NGLW. A detailed comparison between the two welding conditions will be presented in the next section.
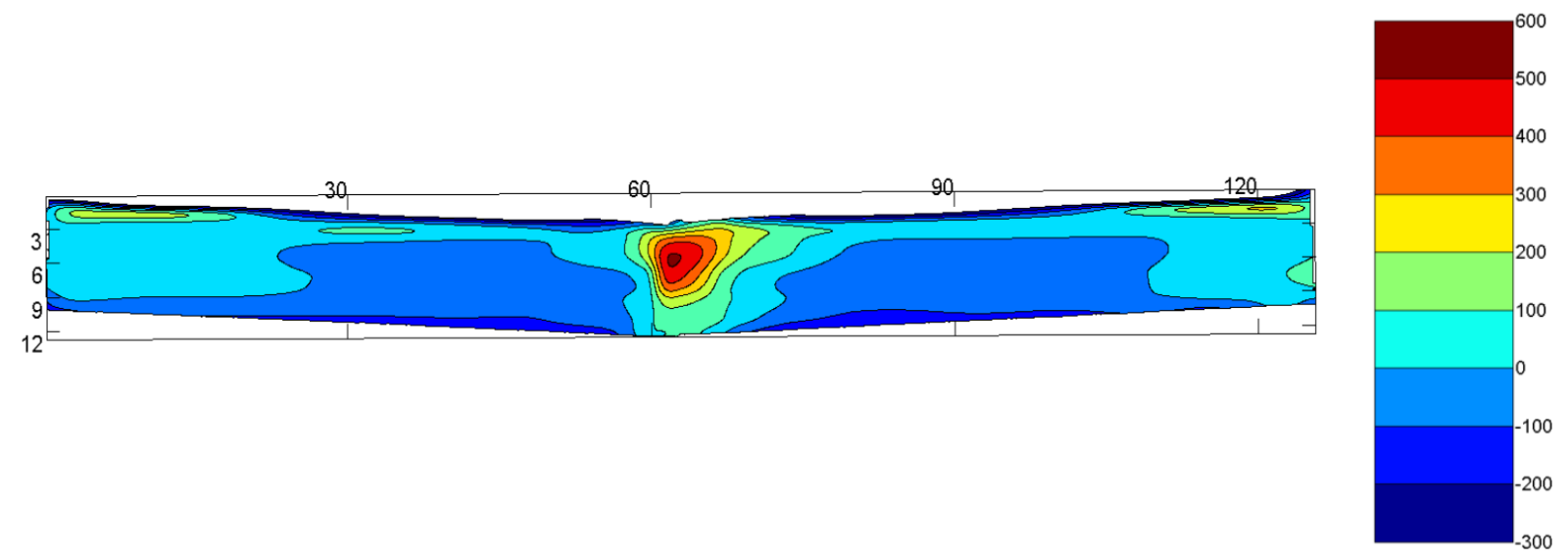

Figure 12: Longitudinal residual stress profile for high power NGLW sample [MPa]- the laser power was $4 \mathrm{~kW}$ and the welding speed was $0.72 \mathrm{~m} / \mathrm{min}$ 


\subsection{Neutron diffraction measurements for low power NGLW}

Figure 13 shows the longitudinal residual stresses for the low power NGLW plate, as measured by neutron diffraction. The results show that a relatively narrow region of tensile stress exists close to the weld centreline, and that this region extends to approximately $10 \mathrm{~mm}$ from the centreline. The highest value of stress is close to $400 \mathrm{MPa}$ and this was measured on the weld centreline $2 \mathrm{~mm}$ below the top surface. A secondary peak also occurs on the weld centreline at a depth of $7 \mathrm{~mm}$. The stresses rapidly decrease with increasing distance from the weld centreline towards the edge of the sample.

A notable exception to this trend occurs at a distance of $4 \mathrm{~mm}$ from the weld centreline, where there is a local dip in the stress. This dip is likely to be an artefact caused by a discrepancy in the value of $d_{\text {ref }}$, the stress-free lattice parameter at that location.

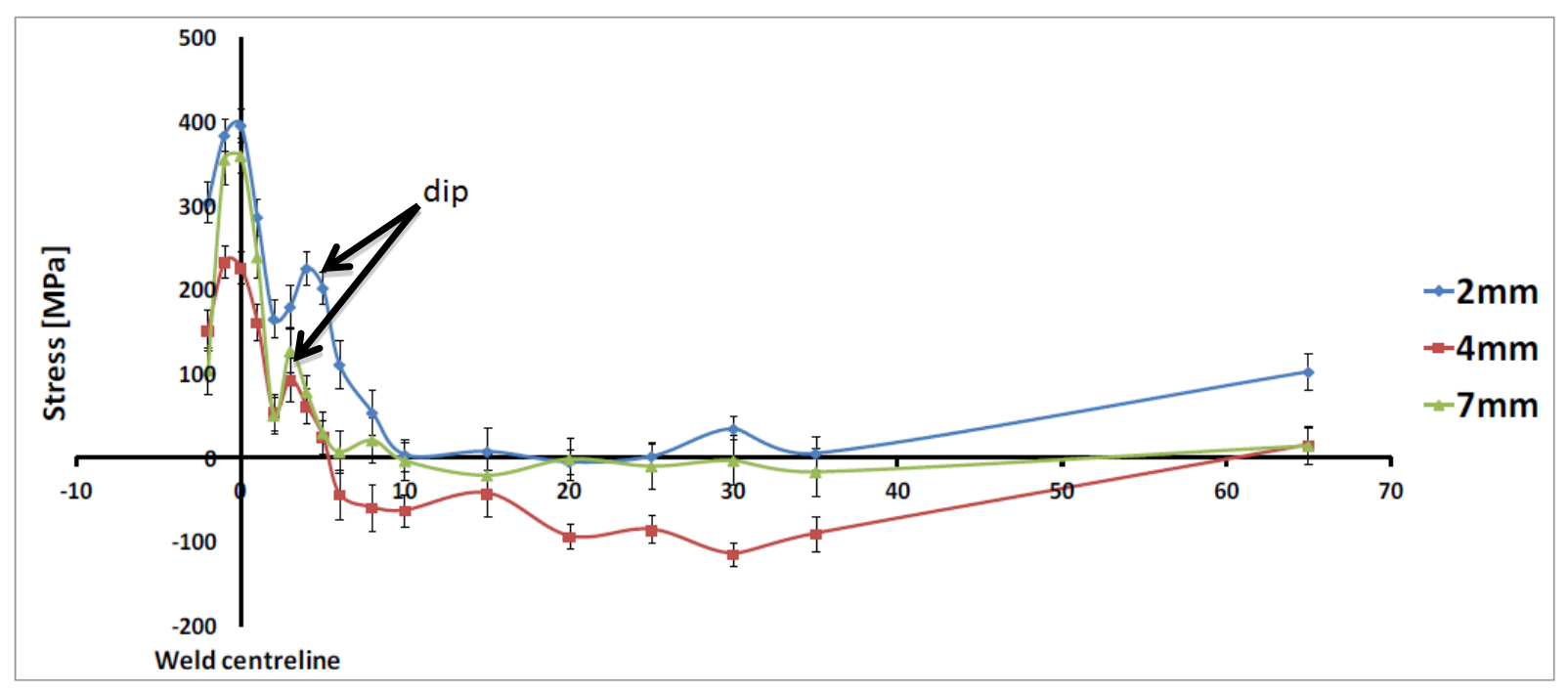

Figure 13: Longitudinal residual stresses for the low power NGLW sample at different depths as measured by neutron diffraction.

Figure 14 compares the three components of residual stress in the low power NGLW sample at a distance of $2 \mathrm{~mm}$ below the top surface. As might be expected, the highest stresses $(\sim 400$ MPa) were measured in the longitudinal direction, followed by the transverse direction $(\sim 200$ $\mathrm{MPa})$, and finally the normal direction $(\sim 100 \mathrm{MPa})$. 


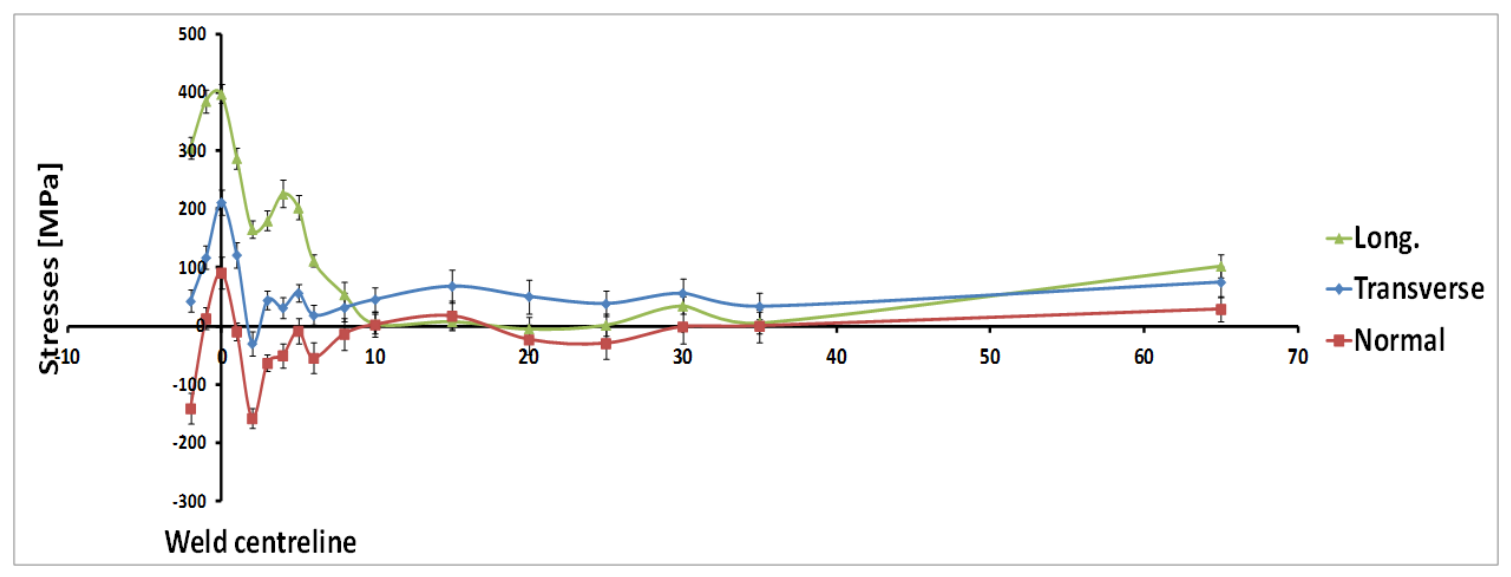

Figure 14: Longitudinal, transverse, and normal stresses for the low power NGLW sample as a function of distance from the weld centreline. The measurements were made at a depth of 2 $\mathrm{mm}$ below the top surface using the neutron diffraction technique.

\subsection{Comparison of residual stresses for high and low power welds}

The longitudinal residual stress distributions for the high power ( $4 \mathrm{~kW}$ and 4 filling passes) and the low power ( $1 \mathrm{~kW}$ and 10 filling passes) NGLW samples are compared in Figure 15. The data were obtained using the contour method and they correspond to a depth of $3 \mathrm{~mm}$ below the top surface of the plate. The results show that the peak stresses coincide with the weld centreline, and that the stress distributions are approximately symmetric for both welding conditions. The peak value of residual stress for the high power welding parameters is approximately $600 \mathrm{MPa}$, but this decreased to $\sim 350 \mathrm{MPa}$ for the low power welding conditions. The width of the tensile region can also be seen to be significantly higher in the high power specimen $(\sim 25 \mathrm{~mm})$ than in the low power specimen $(\sim 15 \mathrm{~mm})$.

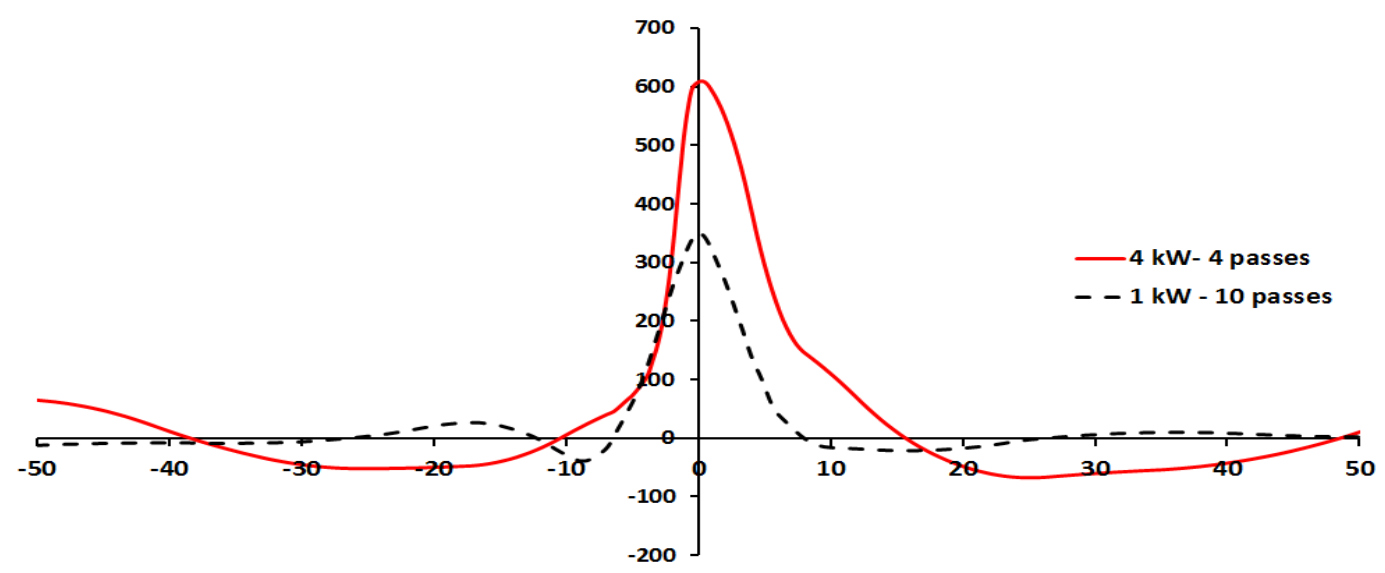

Figure 15: Longitudinal residual stress distributions for high-power and low-power NGLW as measured by the contour method. The stresses were obtained at a depth of $2 \mathrm{~mm}$ below the top surface of each plate. The horizontal axis shows distance from the weld centreline $(\mathrm{mm})$ and the vertical axis shows residual stress $(\mathrm{MPa})$. 
The results in Figure 15 suggest that the residual stress distributions for NGLW are quite sensitive to laser power, with an increase in laser power leading to an increase in the peak value of residual stress and also to the width of the tensile region. This would suggest that, from a structural integrity standpoint, there may be benefits associated with using a lower welding power and a higher number of weld passes when joining thick cross sections. However, in making such a choice there would be a trade off with welding productivity, since a reduction in laser power will lead to an increase in the number of passes required to complete the weld.

\subsection{Comparison of contour method and neutron diffraction measurements on NGLW samples}

In Figure 16 the residual stress measurements made with the contour method on the low power NGLW sample are compared with those obtained by neutron diffraction. The stresses obtained at a distance of $2 \mathrm{~mm}$ below the top surface are shown in Figure 16a, while those obtained at the mid-thickness position are shown in Figure 16b. While there are slight differences between the stress distributions obtained with each measurement technique, the agreement is excellent overall at both through-thickness positions. The fact that good agreement was achieved between measurements obtained with dissimilar techniques adds credibility to the trends that have been observed. 
(a)
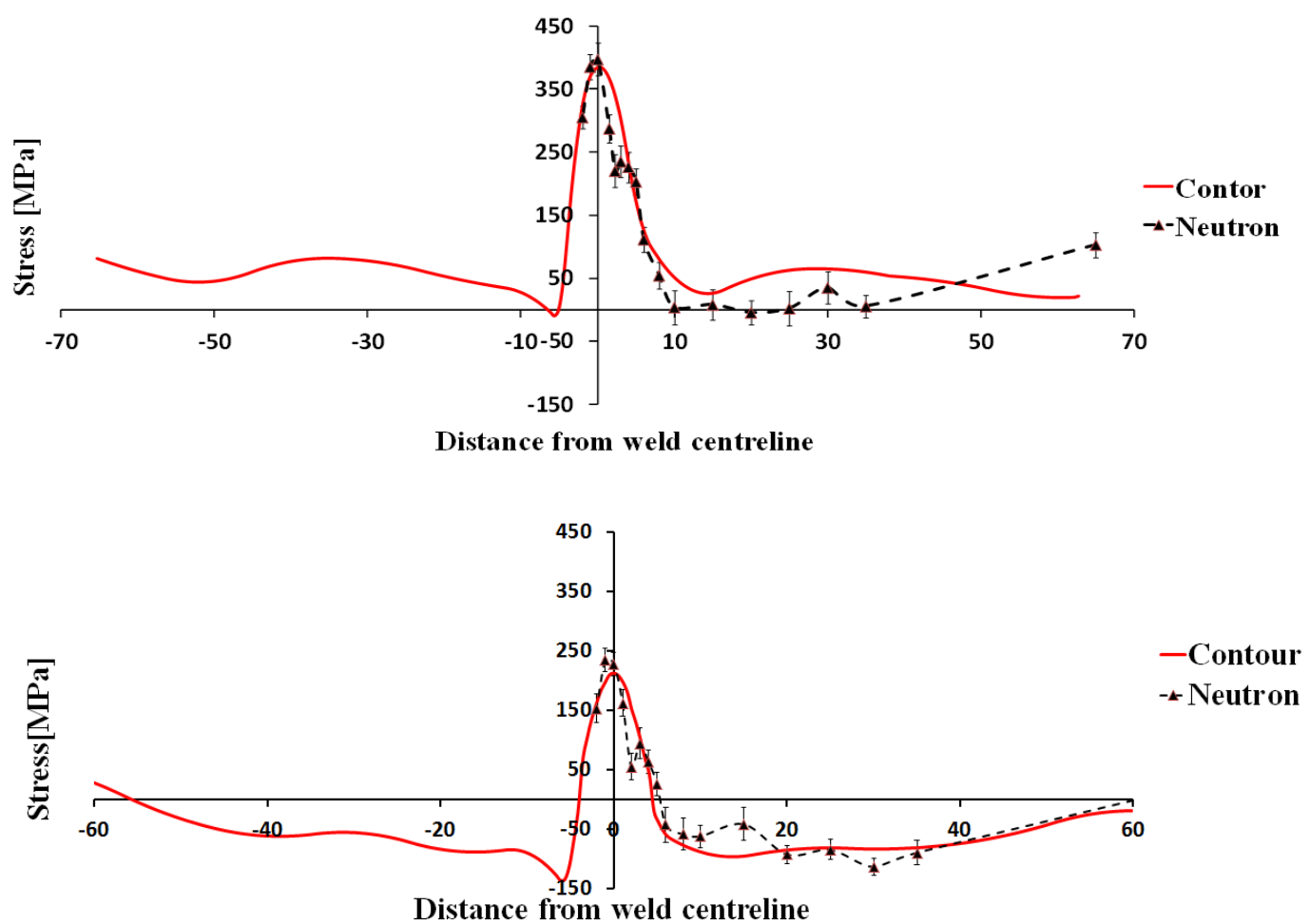

(b)

Distance from weld centreline

(a) $2 \mathrm{~mm}$ below top surface

(b) Mid-depth

Figure 16: Comparison of longitudinal residual stresses in the low power NGLW sample as measured by neutron diffraction and the contour method, at (a) a depth of $2 \mathrm{~mm}$ below the top surface of the plate and (b) at the mid-depth position.

\subsection{Residual stresses in high power autogenous laser welds}

Figure 17 shows the longitudinal residual stress distribution for a single pass autogenous laser weld in a $10 \mathrm{~mm}$ thick plate. The residual stresses were determined with the contour method. The welding parameters included a laser power of $7.5 \mathrm{~kW}$ and a welding speed of $0.6 \mathrm{~m} / \mathrm{min}$. The results show a peak tensile stress of around $650 \mathrm{MPa}$ coinciding with the fusion zone. The high laser power appears to have led to an increase in the magnitude of the residual stresses when compared to the NGLW samples. 


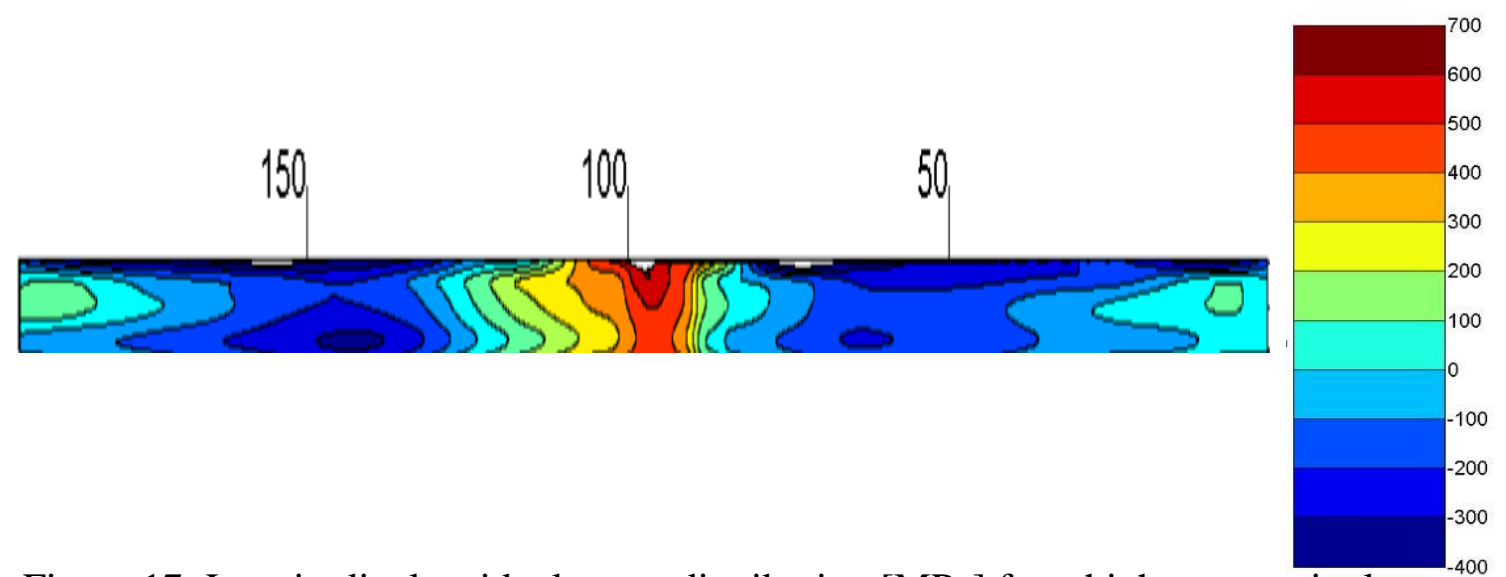

Figure 17: Longitudinal residual stress distribution [MPa] for a high power, single pass autogenous laser weld in a $10 \mathrm{~mm}$ thick plate

\subsection{Comparison of contour method and neutron diffraction measurements on single pass autogenous laser weld}

The residual stress measurements made on the single pass autogenous laser weld using the contour method are compared with those made by neutron diffraction in Figure 18. All measurements were made at a depth of $2 \mathrm{~mm}$ below the top surface of the plates. The welding parameters were similar to the parameters described in the previous section. The results obtained with each technique are in good agreement, with both methods indicating that the peak value of tensile stress is $\approx 670 \mathrm{MPa}$ and that the width of the tensile region is $\approx 50 \mathrm{~mm}$.

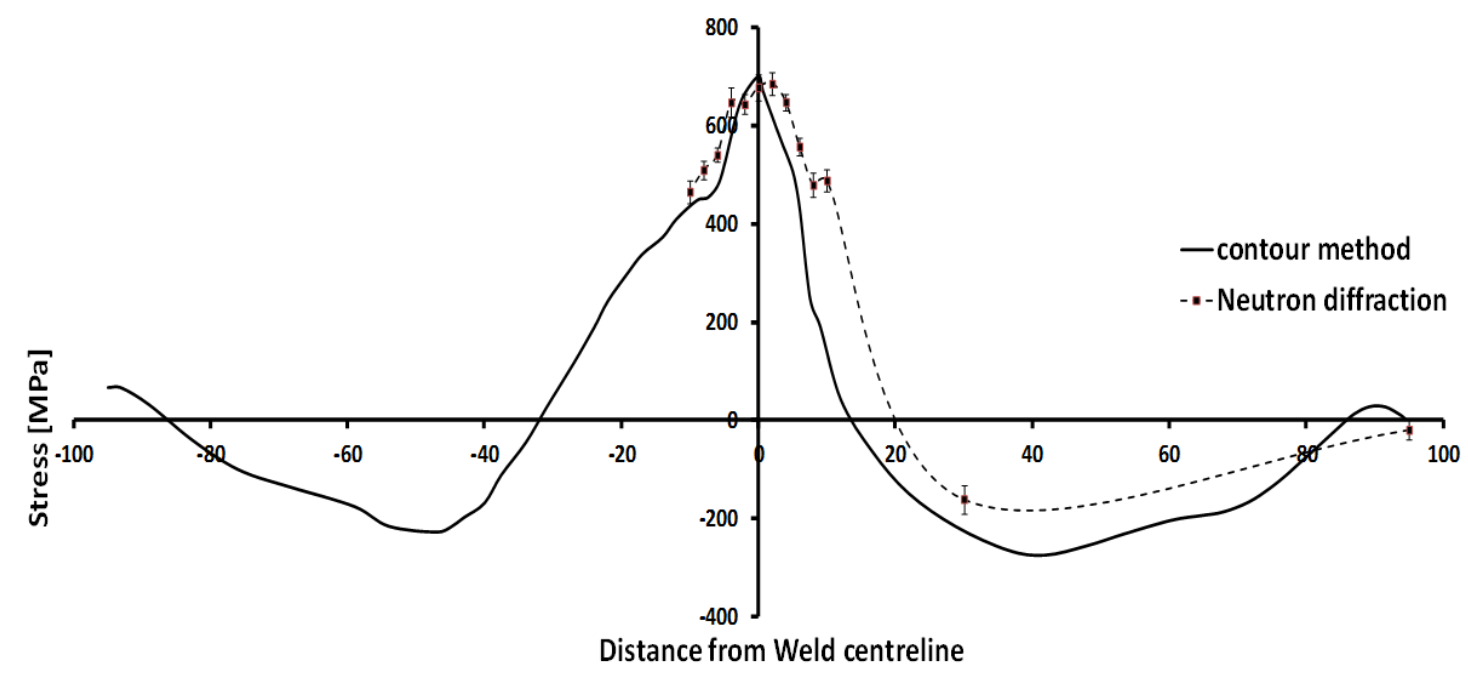

Figure 18 Longitudinal residual stress distributions for the high power autogenous laser weld, 2 $\mathrm{mm}$ below the top surface of the plates, as measured by neutron diffraction and the contour method.

The three orthogonal components of residual stress for the high power laser weld in $10 \mathrm{~mm}$ thick fully restrained plates, as determined by neutron diffraction, are shown in Figure 18. The 
peak value of the longitudinal residual stress can be seen to be higher than yield stress for AISI $316 \mathrm{~L}$ stainless steel. However the deviatoric stress is $\approx 320 \mathrm{MPa}$, which is much closer to the yield stress for this material.

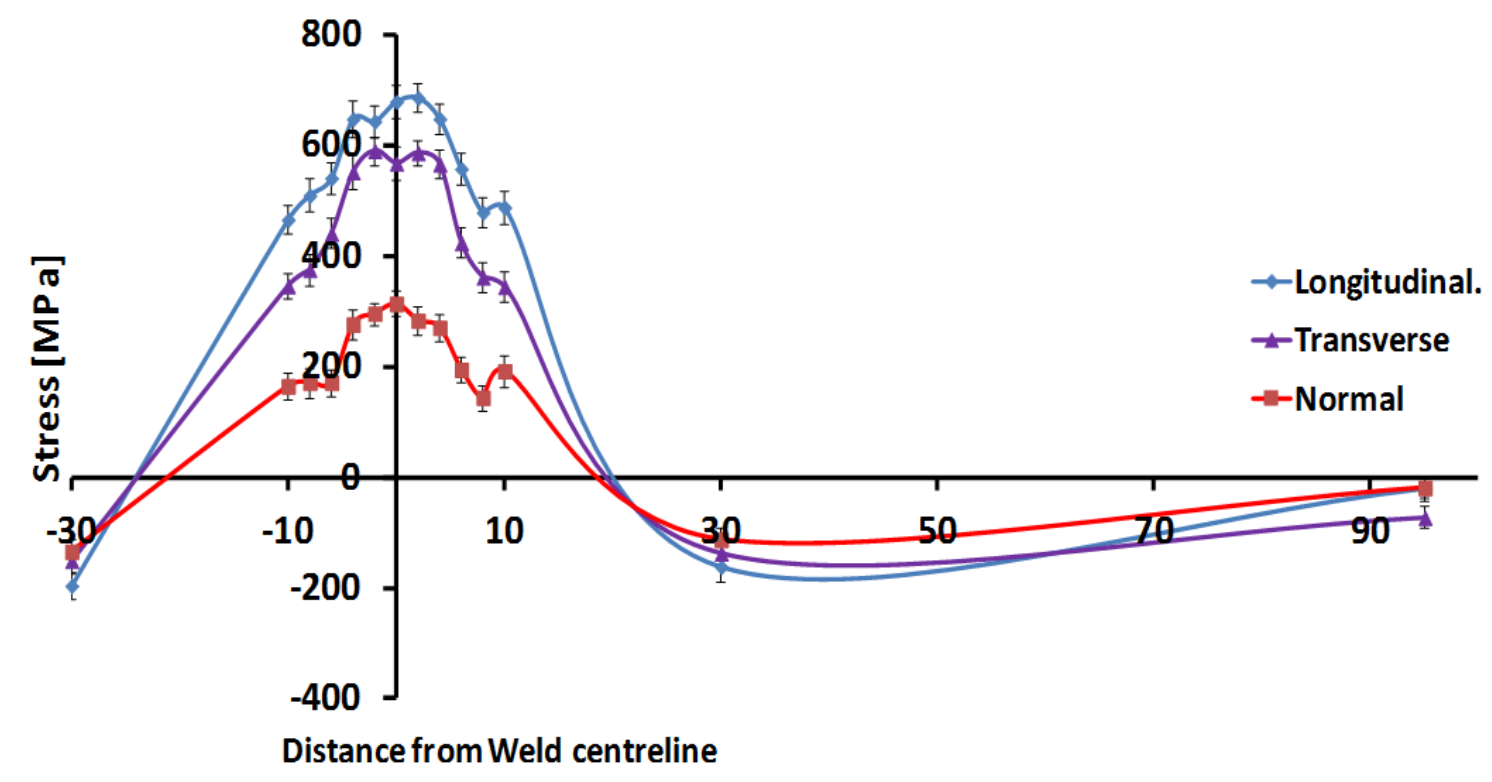

Figure 19. Longitudinal, transverse, and normal components of residual stress, $2 \mathrm{~mm}$ below the top surface of the $10 \mathrm{~mm}$ thick plate, for the HPLW as measured using neutron diffraction.

\subsection{Finite element modelling of the NGLW process}

\subsubsection{Influence of welding parameters on the residual stress distribution for autogenous high power laser welding}

The influence of laser power and welding speed on the residual stress distribution for a high power autogenous laser weld in a $10 \mathrm{~mm}$ thick plate was investigated. The welding parameters were varied as follows; the power was decreased to $5 \mathrm{~kW}$, and the welding speed was increased to $960 \mathrm{~mm} / \mathrm{min}$. The results of experimental investigations suggested that these parameters would be sufficient to produce a full penetration weld in $10 \mathrm{~mm}$ thick plates. The longitudinal residual stress distribution across the weld was evaluated using the contour method. The resulting measurements show that both the value of the peak tensile stress and width of the tensile region decrease if these parameters are employed (Figure 20). 

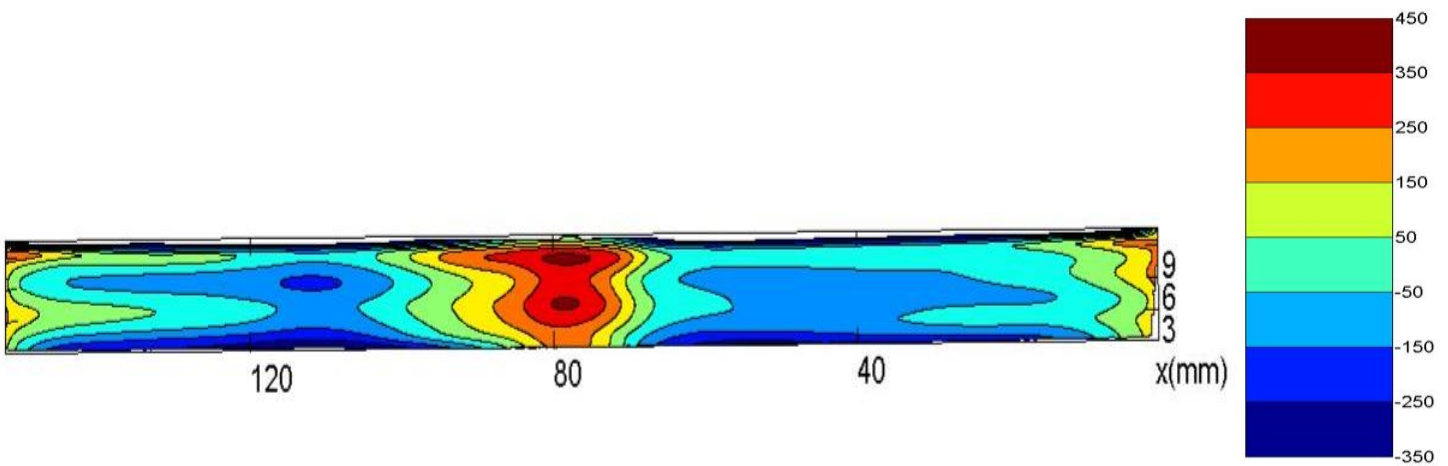

Figure 20 Residual stress distribution [MPa] measured using the contour method for a single pass autogenous laser weld in a $10 \mathrm{~mm}$ thick plate, using a reduced power $(5 \mathrm{~kW})$ and an increased speed $(960 \mathrm{~mm} / \mathrm{min})$

Other welded samples were used in order to compare the residual stress distributions for the two sets of welding parameters at a distance of $2 \mathrm{~mm}$ below the top surface of the plates (Figure 21$)$. For the high power $(7.5 \mathrm{~kW})$ and low speed $(660 \mathrm{~mm} / \mathrm{min})$ case the peak tensile stress was $\approx 650 \mathrm{MPa}$, and the width of the tensile region was $\approx 50 \mathrm{~mm}$. When the power was reduced and the welding speed was increased, the peak tensile stress decreased to $\approx 420 \mathrm{MPa}$, and the width of the tensile region decreased to $40 \mathrm{~mm}$, as can be seen in Figure 21. The results show that the welding power and welding speed have a pronounced influence on the peak value of stress, which decreased by $33 \%$. However, the effect on the width of the tensile region was less significant, as it decreased only by $20 \%$. Nevertheless, it would appear that employing a reduced laser power and an increased welding speed offers significant benefits in terms of reducing residual stresses in autogenous laser welds, and that this strategy should be adopted provided that the welding parameters can reliably produce full penetration welds.

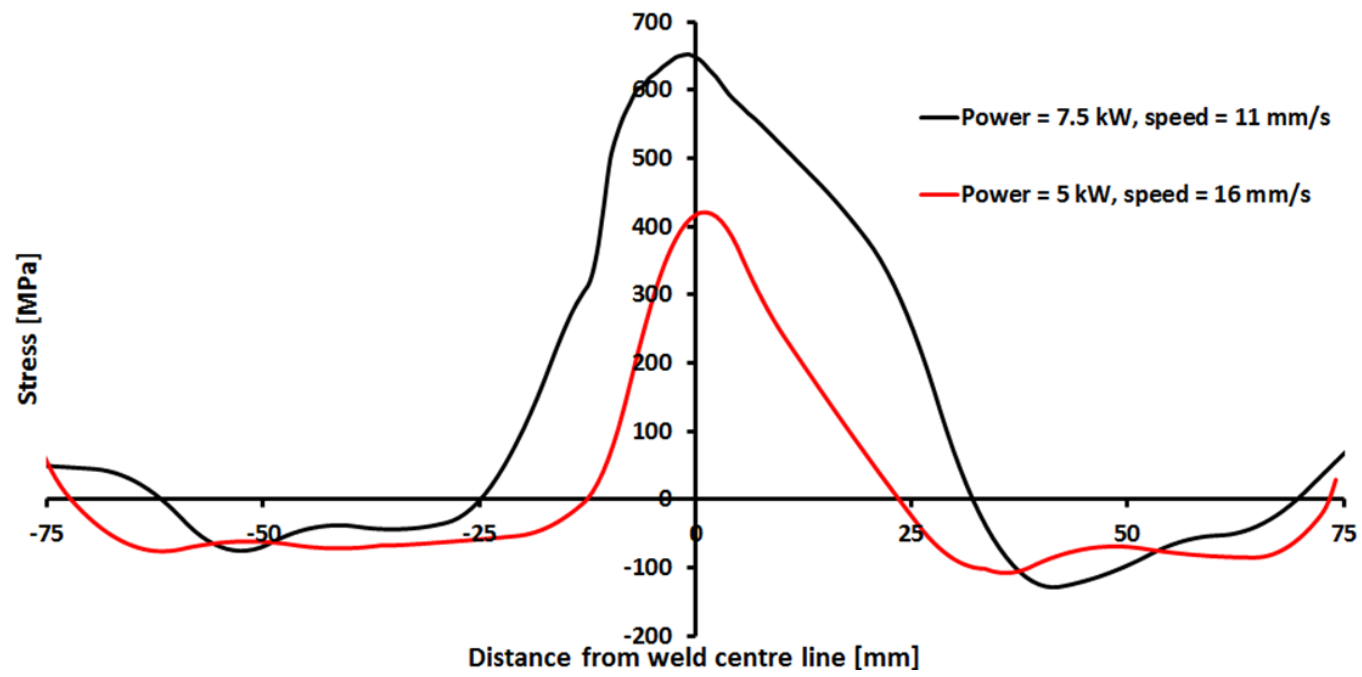

Figure 21. Residual stress profiles measured using the contour method at a distance of $2 \mathrm{~mm}$ below the top surface of the plates for autogenous high power laser welds made with different welding parameters 


\subsubsection{Effects of welding parameters on thermal history of welded joints}

The effects of welding parameters on residual stress distributions can be explained in terms of the influence the welding parameters have on the temperature fields. Figure 22 shows predictions for the peak temperatures that are experienced as a function of position for different combinations of parameters (power and speed). The predictions suggest that with a laser power of $1000 \mathrm{~W}$, and with a welding speed of $9.5 \mathrm{~mm} / \mathrm{s}$, the peak temperature is $\approx 3000{ }^{\circ} \mathrm{C}$, and that the temperature gradients are high due to a low heat input to the welded joint (Figure 22a). The steep temperature gradients would lead to a narrow heat affected zone. With the same power, and with a lower speed $(5 \mathrm{~mm} / \mathrm{s})$, the highest value of the peak temperature is approximately the same, but the temperature gradients are lower, as is shown in Figure 22b. This would result in a larger heat affected zone. With a high power and a high speed, the peak temperature increases to $\approx 4500{ }^{\circ} \mathrm{C}$, but the extent of the heat affected zone is restricted, as is shown in Figure 22c.

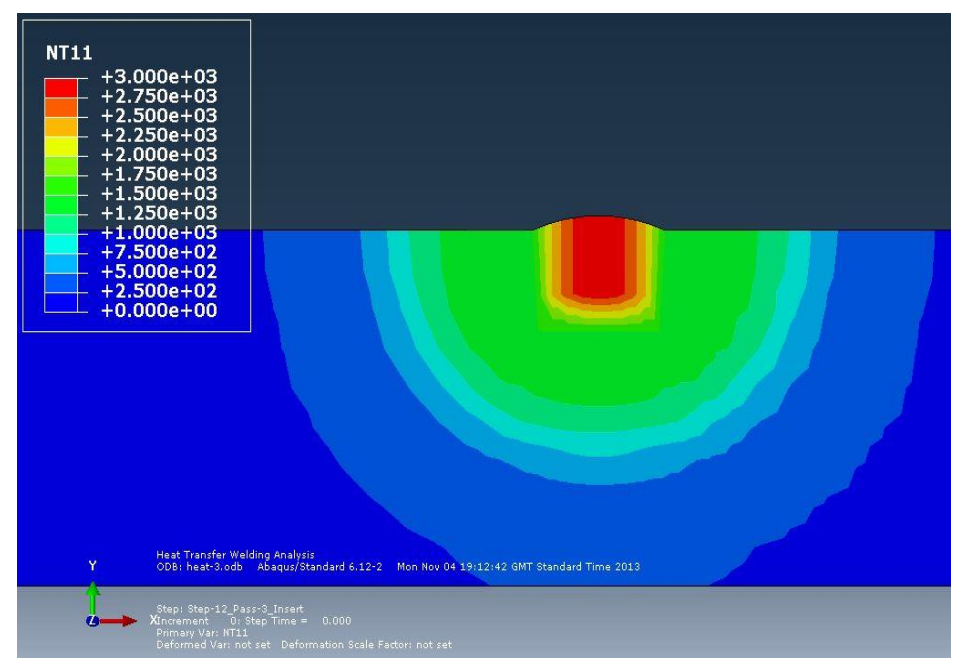

a) power $=1000 \mathrm{~W}$, welding speed $=9.5 \mathrm{~mm} / \mathrm{s}$

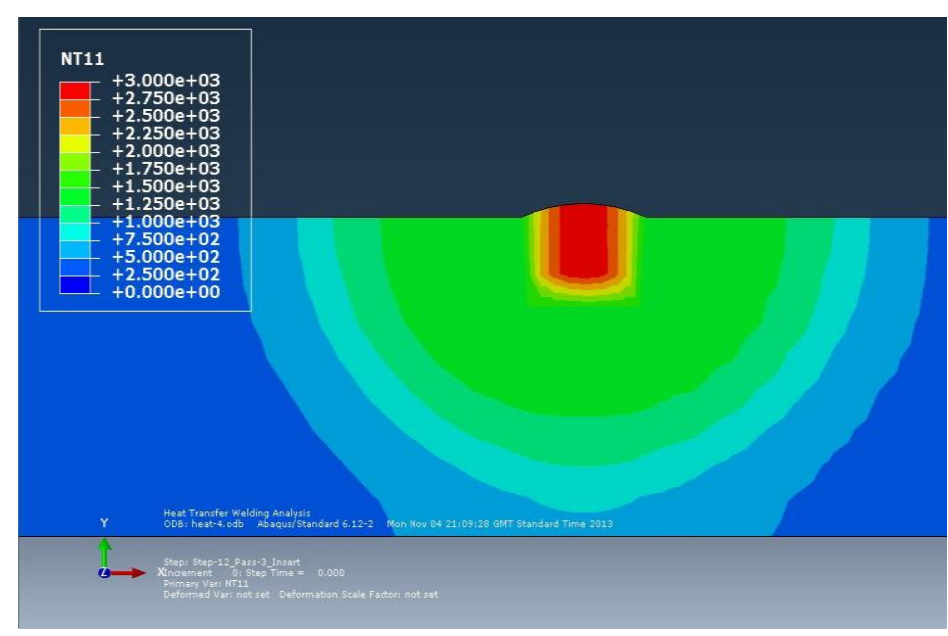

b) power $=1000 \mathrm{~W}$, welding speed $=5 \mathrm{~mm} / \mathrm{s}$ 


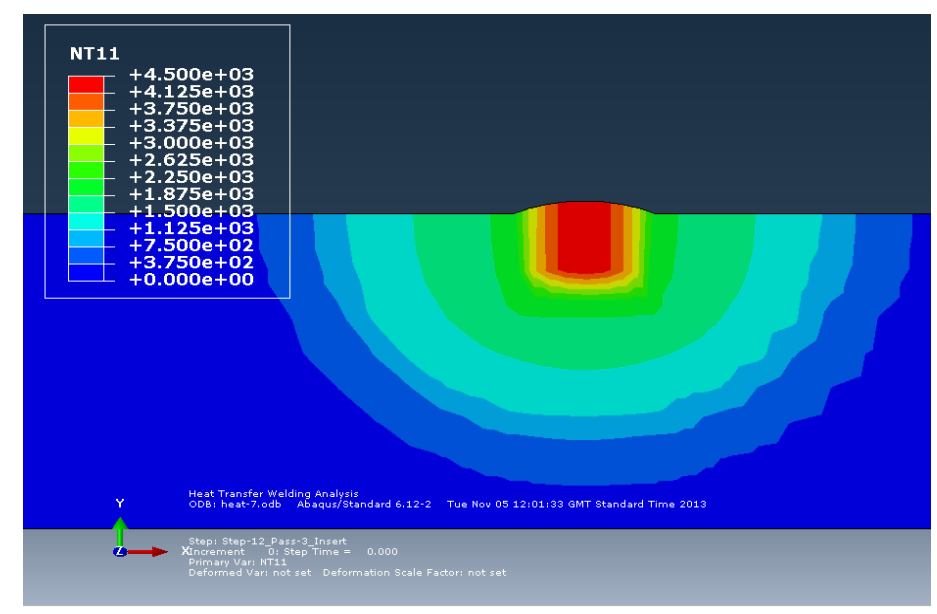

c) power $=1800 \mathrm{~W}$, welding speed $=9.5 \mathrm{~mm} / \mathrm{s}$

Figure 22. Predicted spatial distribution of peak temperatures for different combinations of welding parameters. The plates are $10 \mathrm{~mm}$ thick in each case.

Figure 23 compares temperature distributions for the three combinations of welding parameters. The red curve corresponds to the predictions for a power of $1000 \mathrm{~W}$ and a welding speed of $9.5 \mathrm{~mm} / \mathrm{s}$. The predicted peak temperature is $3000^{\circ} \mathrm{C}$, and the width of the heated region is $\approx 3 \mathrm{~mm}$. Increasing the power to $1800 \mathrm{~W}$ leads to an increase in the predicted peak temperature (to $4500^{\circ} \mathrm{C}$ ) with no significant influence on the width of the heated region. On the other hand, decreasing the welding speed to $5 \mathrm{~mm} / \mathrm{s}$ has a significant influence on the width of the heated region, which is close to $6 \mathrm{~mm}$ wide.

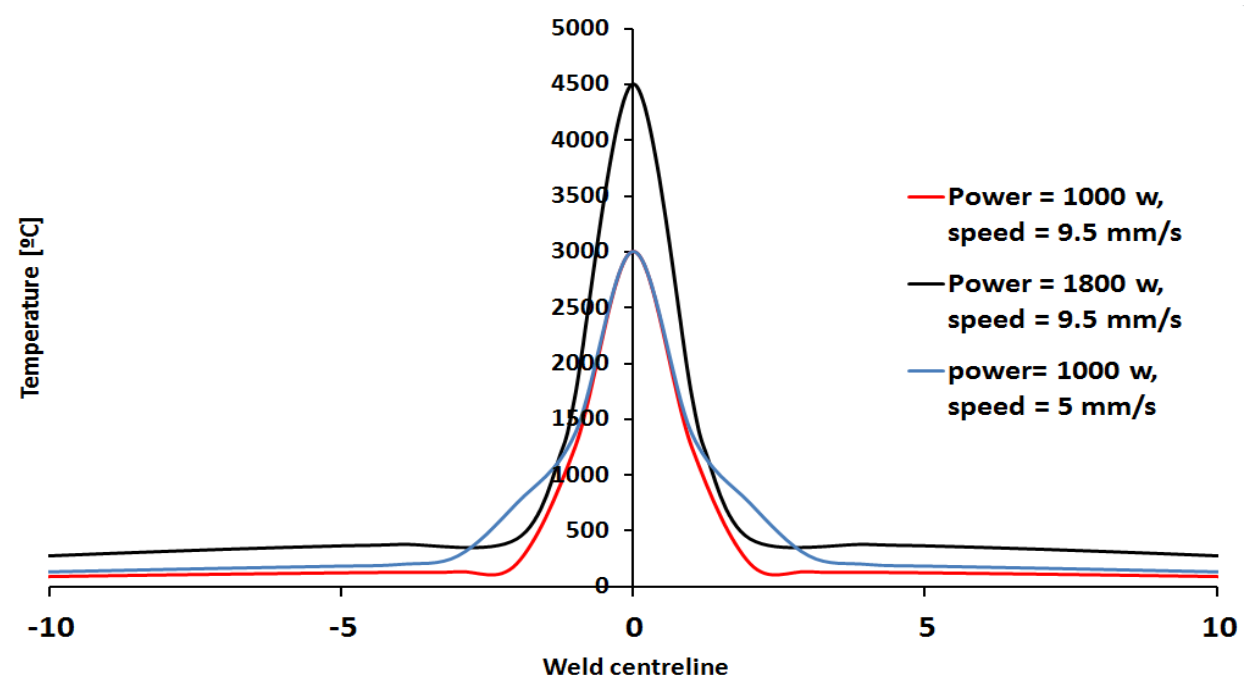

Figure 23. Comparison of temperature profiles predicted using the Abaqus Welding Interface (AWI) for different combinations of welding parameters 


\subsubsection{Results of mechanical model}

The input for the mechanical analysis is the temperature history (thermal loading) obtained from the thermal analysis. The thermal strains and stresses can be calculated at each time increment. The final state of residual stress is determined from the accumulation of thermal strains and stresses for all previous passes. During each weld pass, stresses were calculated from the temperature distributions determined by the thermal model. The von Mises yield criterion was used to model plastic deformation, and isotropic strain hardening was assumed.

Figure 24 compares the predicted residual stress distribution for the $10 \mathrm{~mm}$-thick NGLW plate, welded with optimum parameters (i.e. using 10 filling passes) [9], with the results obtained using the contour method. The results show a narrow region sustaining tensile residual stresses, with a peak value of stress in the order of $400 \mathrm{MPa}$. The stresses reduce to values near to zero within $10 \mathrm{~mm}$ of either side of the weld centreline. With increasing distance from the weld centreline, compressive stresses arise on both sides (with values up to $\sim 150 \mathrm{MPa}$ ), and finally the stresses decay towards the outer edges of the plate. The agreement between the predicted and measured stress distributions is generally very good. Most details of the stress distribution obtained with the contour method were captured in the predicted stress distribution. While the lower peak in tensile stress observed in the contour method results was not captured clearly in the modelling results, this peak is very shallow, and by increasing the scale it was found to be captured to some degree, as can be seen in Figure 24.

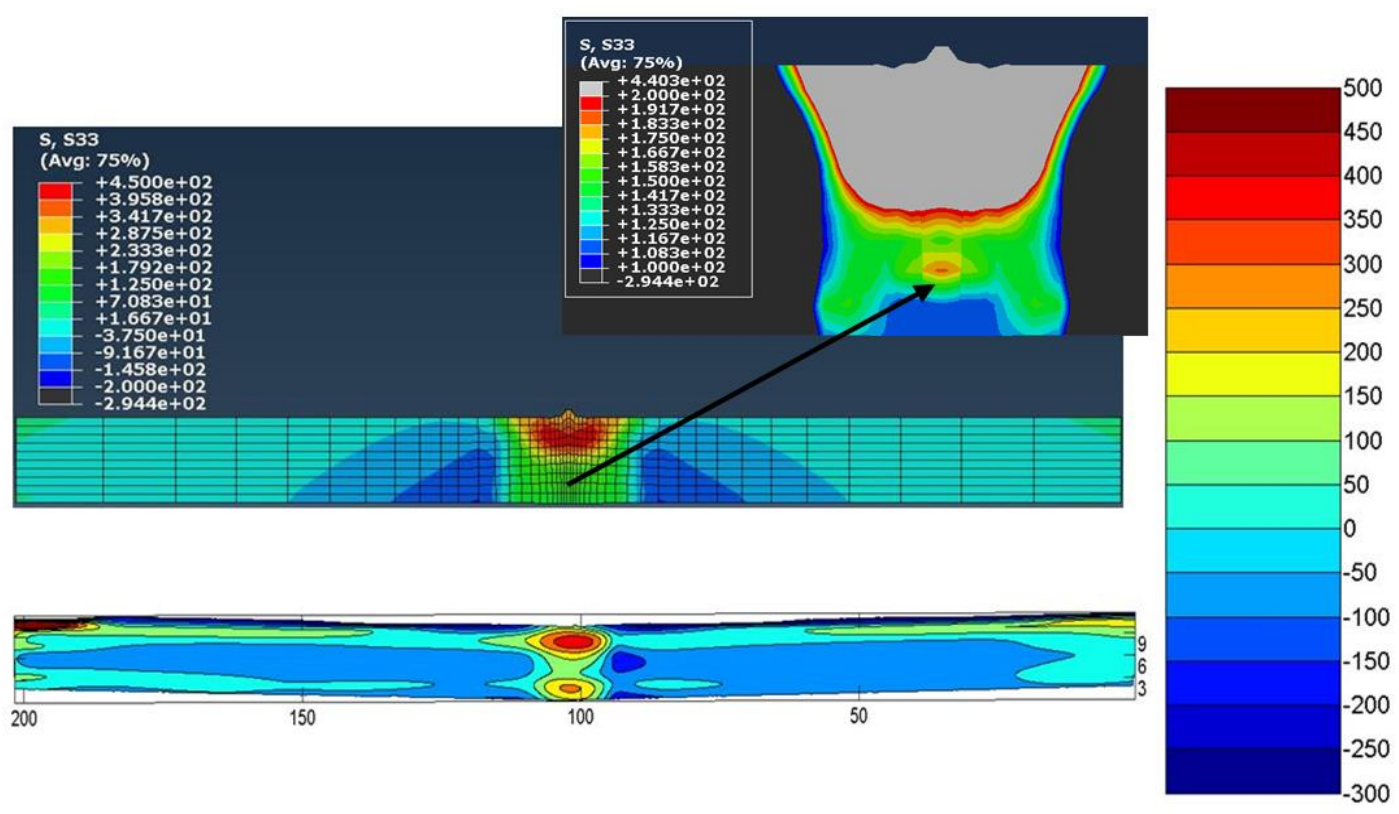

Figure 24 Comparison of predicted residual stress distribution (top) with the distribution measured using the contour method (bottom) for the low power $10 \mathrm{~mm}$ thick NGLW 


\subsubsection{Validation of modelling results against contour and neutron diffraction methods}

Figure 25 compares the predicted residual stresses in the $10 \mathrm{~mm}$ thick NGLW plate with measurements made using the contour method and neutron diffraction. To enable the comparison, the longitudinal residual stresses were evaluated at a depth of $2 \mathrm{~mm}$ from the upper surface. The measurement line was perpendicular to the welding direction, as is shown in Figure 25. The comparison shows a very good correlation between the three evaluation methods. The peak tensile stress at the centreline is $\sim 400 \mathrm{MPa}$, and the stress rapidly reduces to zero stress at a distance of $10 \mathrm{~mm}$ from the weld centreline.

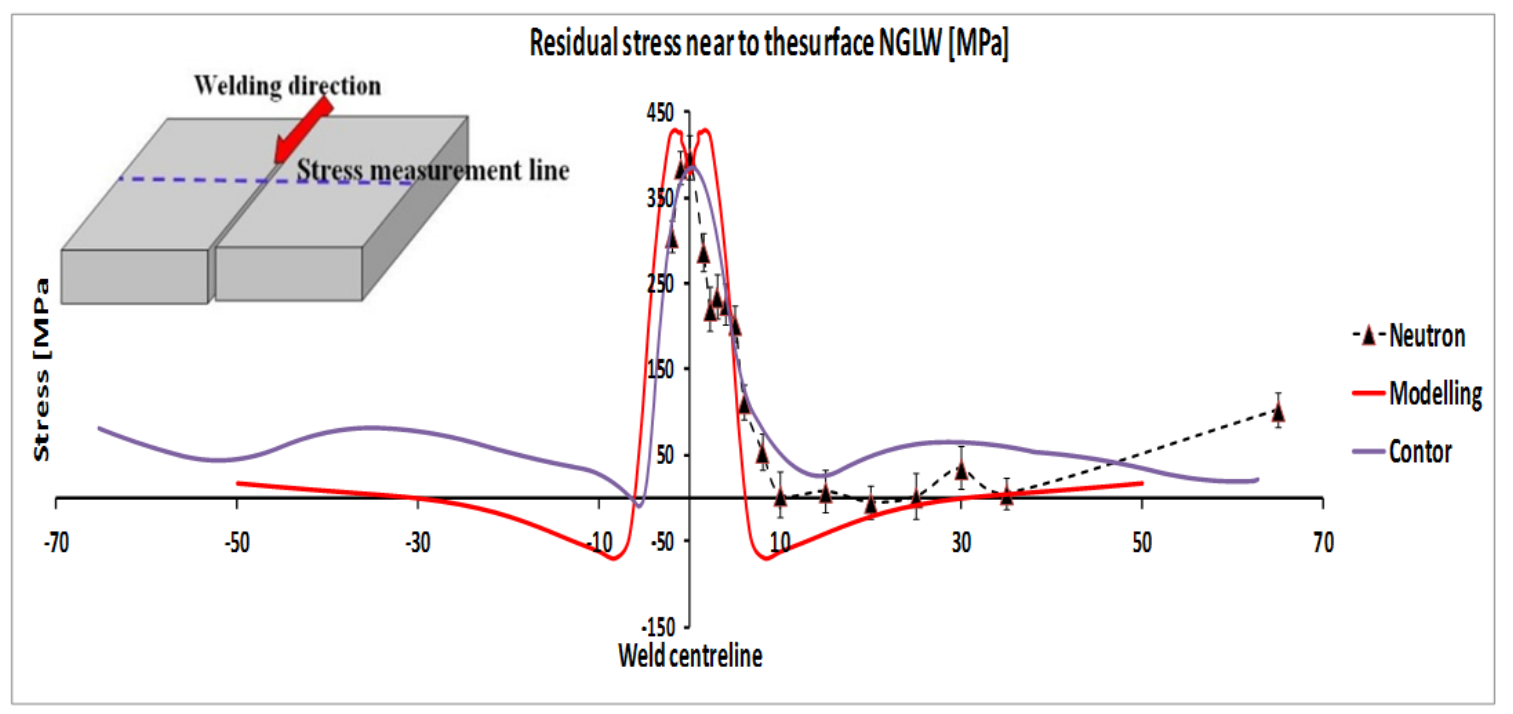

Figure 25 Comparison of predicted longitudinal residual stresses [MPa] in the low power NGLW in a $10 \mathrm{~mm}$ thick plate with those measured using the contour method and neutron diffraction. All values correspond to a distance of $2 \mathrm{~mm}$ below the top surface.

Figure 26 shows predictions for the longitudinal residual stress distributions in $3 \mathrm{~mm}$ thick samples. Two different values for laser power were investigated in order to assess any potential effects on the resulting stresses. The predictions in Figure 26a correspond to a laser power of $1000 \mathrm{~W}$ and a welding speed of $9.5 \mathrm{~mm} / \mathrm{s}$, while those in Figure $26 \mathrm{~b}$ correspond to the lower power of $750 \mathrm{~W}$. The predicted residual stress distributions can be seen to have a similar configuration, but the stresses reduce significantly when the laser power is reduced.

Figure 26c compares the residual stress distributions at a depth of $2 \mathrm{~mm}$ from the upper surface for both sets of welding parameters. Again, the patterns in the residual stress distributions are similar, but the lower laser power $(750 \mathrm{~W})$ leads to a lower value for the peak tensile residual 
stress (200 MPa). While the width of the region sustaining tensile stresses is slightly narrower with the lower power, the most significant influence of laser power is on the peak stress.

\subsubsection{Influence of laser power on residual stresses}

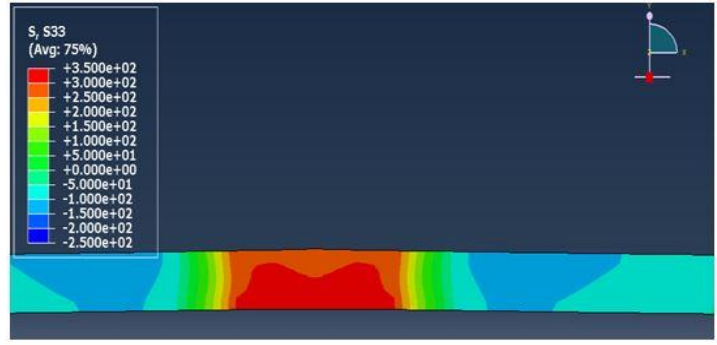

(a)

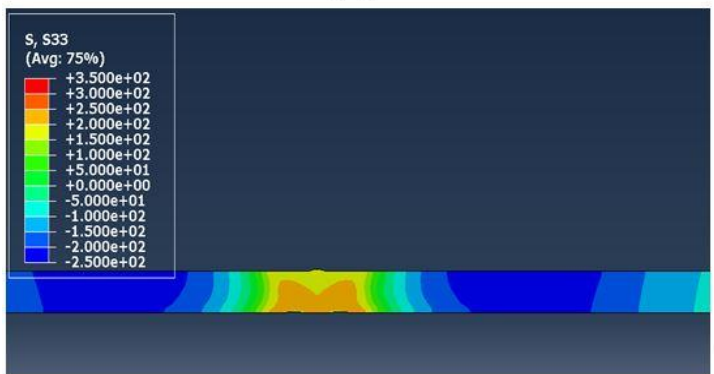

(b)

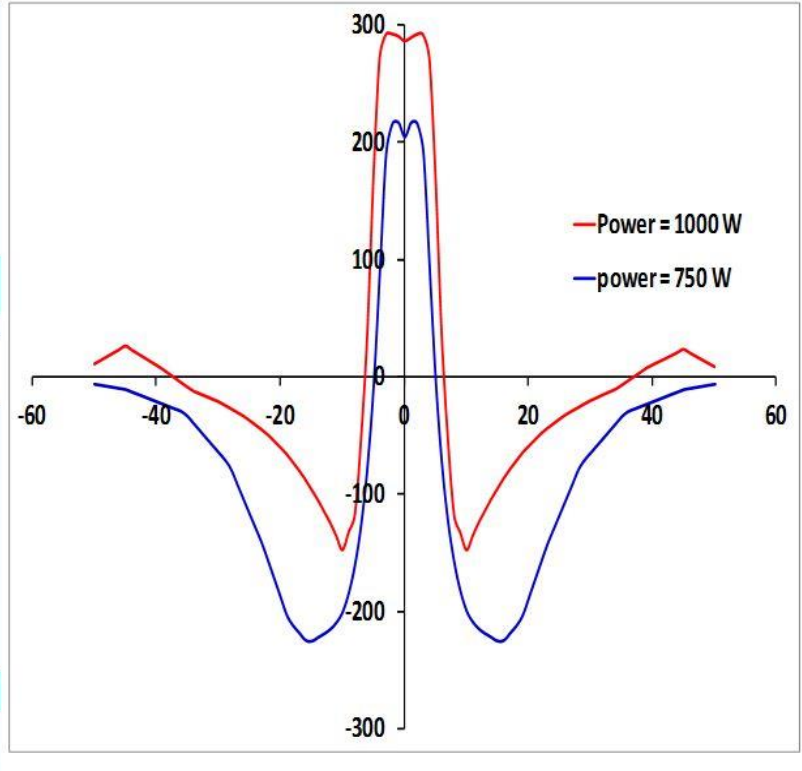

(c)

Figure 26 Predicted residual stresses in $3 \mathrm{~mm}$ thick plates for laser powers of (a) $1000 \mathrm{~W}$ and (b) $750 \mathrm{~W}$. In (c) the predictions correspond to a distance of $2 \mathrm{~mm}$ below the top surface of the plate. The horizontal axis in (c) gives the distance from the weld centreline (mm) and the vertical axis shows the predicted stresses. All stresses are in MPa.

\subsubsection{Influence of welding speed on residual stresses}

The influence of the welding speed on the generation of residual stresses was investigated, and the resulting predictions are shown in

Figure 27. The predictions show that a decrease in the welding speed leads to tensile stresses existing over a wider region. The predicted width of the tensile region for a welding speed of 5 $\mathrm{mm} / \mathrm{s}$ is $22 \mathrm{~mm}$, while for a welding speed of $10 \mathrm{~mm} / \mathrm{s}$ it is $15 \mathrm{~mm}$. The welding speed does not appear to have a significant influence on the peak value of residual stress. 


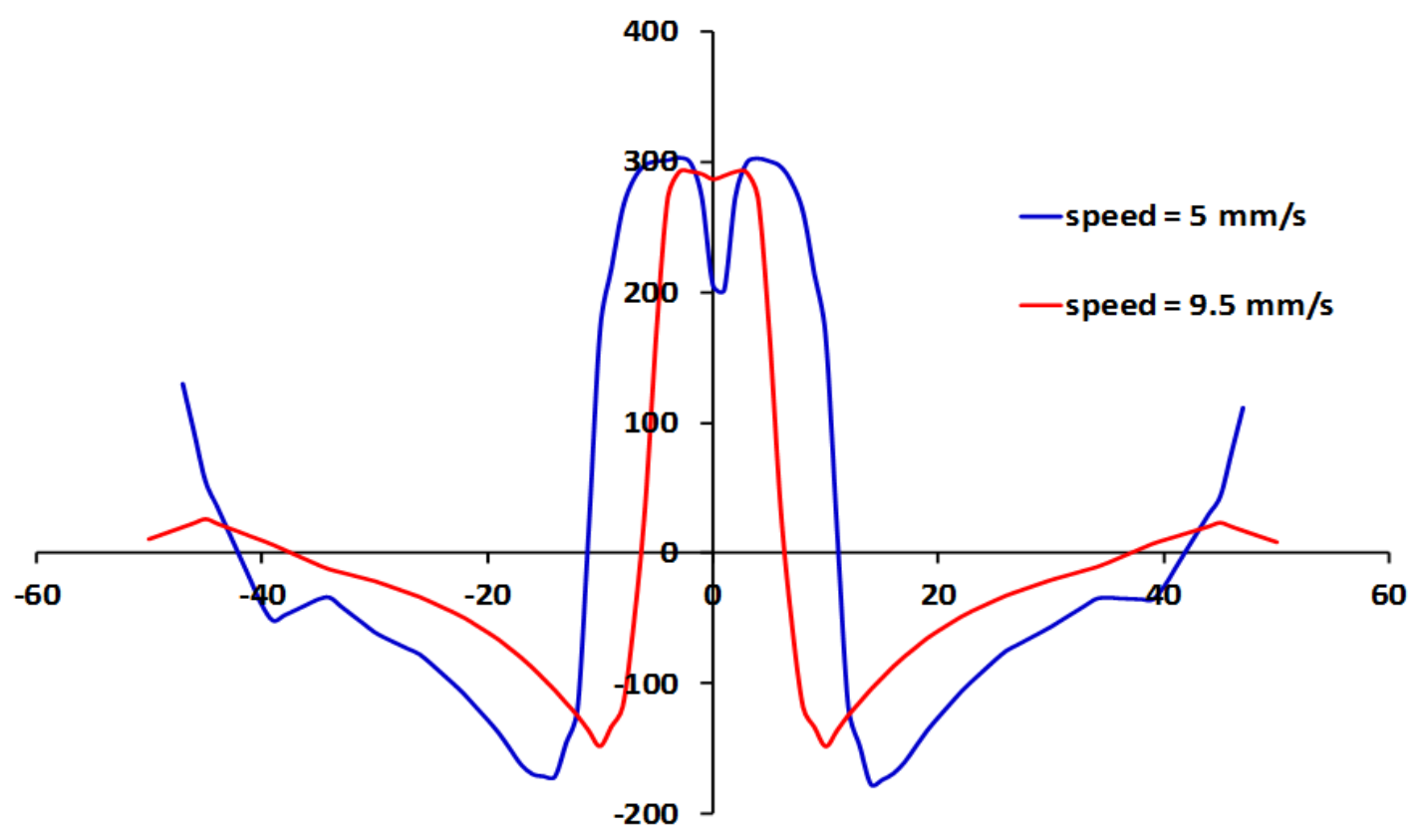

Figure 27 Predicted residual stresses for two different welding speeds. The horizontal axis gives the distance from the weld centreline $(\mathrm{mm})$ and the vertical axis shows the predicted stresses in $\mathrm{MPa}$.

\section{Conclusions}

The following conclusions can be drawn from this work:

The application of the NGLW technique can lead to significant reductions in both the magnitude of the peak tensile residual stresses, and the extent of the region sustaining tensile residual stresses, when compared to high power autogenous laser welds in AISI grade 316L stainless steel.

The reductions in the extent of the regions sustaining tensile residual stresses appear to correlate with the spatial distribution of the peak temperatures in the vicinity of the weld, whereby steeper temperature gradients during welding lead to tensile residual stresses being confined to smaller regions.

The laser power appears to have a strong effect on the magnitude of the peak tensile residual stresses, with an increase in the laser power leading to an increase in the peak stress. In contrast, the laser power does not appear to have a strong effect on the width of the region sustaining tensile residual stresses. 
The welding speed in NGLW has a more significant influence on the width of the region sustaining tensile residual stresses than it does on the peak value of the stress.

\section{Acknowledgments}

- The research reported in this article forms part of a UK EPSRC (Engineering and Physical Sciences Research Council) research programme in Nuclear Manufacturing (NNUMAN) under grant number EP/J021172/1.

- The authors would like to acknowledge the provision of neutron beam time on the SALSA instrument at the Institut Laue-Langevin

- The authors are grateful to Dr. Thilo Pirling and Dr. Zoltan Szaraz for assistance with the neutron diffraction experiment.

\section{References}

[1] Paradowska, A., Price, J.W., Ibrahim, R., Finlayson, T., "A neutron diffraction study of residual stress due to welding," Journal of Materials Processing Technology, vol. 164, pp. 1099-1105, 2005.

[2] Withers, P.J., "Residual stress and its role in failure," Reports on Progress in Physics, vol. 70, p. 2211, 2007.

[3] Zhang, Y., Pratihar, S., Fitzpatrick, M.E., Edwards, L., "Residual stress mapping in welds using the contour method," Materials Science Forum, vol. 490, pp. 294-299, 2005.

[4] Comparison of joining efficiency and residual stresses in laser and laser hybrid welding; Science and Technology of Welding and Joining, 2011 vol. 16 (3) pp. 244-248.

[5] Francis, J.A., Bhadeshia, H. K. D. H. and Withers, P.J. , "Welding residual stresses in ferritic power plant steels," Materials Science and technology, vol. 23, pp. 1009-1020, 2007.

[6] Cheng, X., Fisher, J.W., Prask, H.J., Gnäupel, T., Yen, B.T. Roy, S., "Residual stress modification by post-weld treatment and its beneficial effect on fatigue strength of welded structures," International Journal of fatigue, vol. 25, pp. 1259-1269, 2003.

[7] Hornbach, D.J., Prevéy, P.S., "The effect of prior cold work on tensile residual stress development in nuclear weldments," Journal of Pressure Vessel Technology. Transactions of the ASME, vol. 124, pp. 359-365, 2002. 
[8] Edwards, L., Smith, M.C., Turski, M., Fitzpatrick, M.E., Bouchard, P.J., "Advances in residual stress modeling and measurement for the structural integrity assessment of welded thermal power plant," Advanced Materials Research, vol. 41, pp. 391-400, 2008.

[9] Elmesalamy, A.S., Li, L., Francis, J. A., "A comparison of residual stresses in multi pass narrow gap laser welds and gas-tungsten arc welds in AISI 316L stainless steel," International Journal of Pressure Vessels and Piping, vol. 113, pp. 49-59, 2014.

[10] Elmesalamy, A.S., Li, L., Francis, J. A. and Sezer, H. K., "Understanding the process parameter interactions in multiple-pass ultra-narrow-gap laser welding of thick-section stainless steels," International Journal of Advanced Manufacturing Technology, vol. 68, pp. 117, 2013/01/01 2013.

[11] Pirling, T.B., Giovanni. Withers, Philip J, "SALSA-A new instrument for strain imaging in engineering materials and components," Materials Science and Engineering: A, vol. 437, pp. 139-144, 2006.

[12] Tang, W. and Wang Y., "Fractal characterization of impact fracture surface of steel," Applied Surface Science, vol. 258, pp. 4777-4781, 2012.

[13] Mark, A., Francis, J.A., Dai, H. Turski, M. Hurrell, PR., Bate, SK. Kornmeier, JR. Withers, PJ., "On the evolution of local material properties and residual stress in a three-pass SA508 steel weld," Acta Materialia, vol. 60, pp. 3268-3278, 2012.

[14] Hutchings, M.T., Withers, P. J., Holden, T. M., Lorentzen, T., Introduction to the characterization of residual stress by neutron diffraction: CRC Press, 2005.

[15] Prime, M.B., "Cross-sectional mapping of residual stresses by measuring the surface contour after a cut," Transections of AMSE, Journal of Engineering Materials and Technology, vol. 123, pp. 162-168, 2001.

[16] Pagliaro, P., Prime, M.B., Swenson, H., Zuccarello, B., "Measuring multiple residualstress components using the contour method and multiple cuts," Experimental mechanics, vol. 50, pp. 187-194, 2010.

[17] Kartal, M.E., Liljedahl, C. M., Gungor, S., Edwards, L., Fitzpatrick, M. E., "Determination of the profile of the complete residual stress tensor in a VPPA weld using the multi-axial contour method," Acta Materialia, vol. 56, pp. 4417-4428, 2008. 
[18] Withers, P.J., Turski, M., Edwards, L., Bouchard P.J., Buttle, D.J., "Recent advances in residual stress measurement," International Journal of Pressure Vessels and Piping, vol. 85, pp. 118-127, 2008.

[19] Bouchard, P.J., "Residual Stresses in Lifetime and Structural Integrity Assessment," in Encyclopedia of Materials: Science and Technology (Second Edition), J. Buschow, W. C. Robert, C. F. Merton, I. Bernard, J. K. Edward, M. Subhash, and V. Patrick, Eds., ed Oxford: Elsevier, 2001, pp. 8134-8142.

[20] Ranjbarnodeh, E., Serajzadeh, S., Kokabi, A.H., Fischer, A., "Effect of welding parameters on residual stresses in dissimilar joint of stainless steel to carbon steel," Journal of materials science, vol. 46, pp. 3225-3232, 2011.

[21] Teng, T.L., Chang, P.H., Tseng,W.C., "Effect of welding sequences on residual stresses," Computers \& structures, vol. 81, pp. 273-286, 2003.

[22] Sudnik, W., Radaj, D., Erofeew, W., "Computerized simulation of laser beam welding, modelling and verification," Journal of Physics D: Applied Physics, vol. 29, p. 2811, 1996.

[23] Shanmugam, N.S., Buvanashekaran, G., Sankaranarayanasamy, K., Manonmani, K., "Some studies on temperature profiles in AISI 304 stainless steel sheet during laser beam welding using FE simulation," The International Journal of Advanced Manufacturing Technology, vol. 43, pp. 78-94, 2009.

[24] Balasubramanian, K.R., Siva S. N., Buvanashekaran, G., Sankaranarayanasamy, K., "Numerical and experimental investigation of laser beam welding of AISI 304 stainless steel sheet," Adv Prod Eng Manage J, vol. 3, pp. 93-105, 2008. 


\section{Measurement and modelling of the}

residual stresses in autogenous and narrow gap laser welded AISI grade

\section{L stainless steel plates}

\section{Elmesalamy, A. S.}

Elsevier

A.S. Elmesalamy, H. Abdolvand, J.N. Walsh, J.A. Francis, W. Suder, S. Williams, L. Li, Measurement and modelling of the residual stresses in autogenous and narrow gap laser welded AISI grade 316L stainless steel plates, International Journal of Pressure Vessels and Piping, Volume 147, November 2016, pp.64-78

http://dx.doi.org/10.1016/j.ijpvp.2016.09.007

Downloaded from Cranfield Library Services E-Repository 